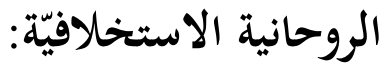

\section{خصائصها وشروطها}

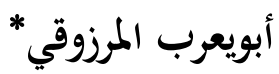

\section{تمهيد}

كيف يمكن أن نعين خصائص الروحانيّة الاستخلافية والشروط المحددة لما؟ وما هي المعيقات التي حالت، إلى الآن، دون إدراكها إدراكا واضحا، ودون إدراك المبادئ التي تساعد على فهم خصائصها العميقة؟ لا نستطيع أن نجيب عن هذين السؤالين جوابا شافيا دون تحديد نظريّة القيم الاستخلافيّة والدليل الوجودي الذي تقوم عليه بصفته جوهرَ التوحيد الاستخلافي. ولا يمكن أن نوفّ إلى الصواب إذا لم نعلم أن مراحل التغلب على هذه المعيقات هي عينها مراحل تاريخ الفكر العربي الإسلامي وحِقَبه الأساسيّة بوصفه سعيَ علماء الإسلامي إلى صياغة هذه الروحانيّة الاستخلافيّة صياغة نظريّة صريحة في علم التوحيد. ذلك أن المعيقات التي حالت دون إدراك خصائص الروحانية الإسلاميّة التي تحققت في الوحي الخاتم (القرآن الكريم)، هي عينها المعيقات التي أصابت الفكر الإنساني، فحالت دون إدراكه خاصيات الروحانيّة الإسلاميّة بما هي جوهر كل الروحانيات المعلومة الأخرى، غاية لها لم تتحق تحقَّها الكامل إلاّ في القرآن.

وستبيّن لنا دراسة الخصائص العامة للروحانية الإسلامية أنه يهق لنا أن نجمع كل هذه المعيقات تحت عنوانٍ واحد، هو الفصل غير المشروع بين التجربة الدينيّة الصوفيّة والتجربة الفلسفيّة العلميّة، وأن نعدّ المبادئ التي تفهِمنا هذه الخصائص العميقة، منحصرة في فروع نظريّة القيم الإسلاميّة التي تنبع من أصل واحد هو نظريّة الشهود، أو الاستخلاف بوصفه رسالة تاريخيّة تحقق قيمَ الإسلام في التاريخ، ولا تكتفي بالدعوة إليها. وتلك هي الثورة الخمميّة التي لم تكن بتربة فاشلة كما يزعم هيجل ولم يكن الإصلاح 
الإنجيلي نظيرها الناجح. ${ }^{1}$ فهذا الإصلاح الموهوم لم يكن إلا صياغة جديدة جمعت بين التحريفين اللذين أصابا رسالتيّ موسى وعيسى -عليهما السلام- فأدت إلى الأفلاطونيّة المحدثة الجرمانيّة التي تناولناها في بحث سابق ${ }^{2}$ شكليْها الرأسمالي الوضعي والشيوعي الماركسي (ونظائرها النقديّة من المنطلق نفسه في الروحانيّة الحلولية). وسنحاول في هذا البحث دراسة خصائص الروحانية الإسلامية عبر مراحل ثلاث، نبرز في أولاها المعيقات والمبادئ، ونعيّن في ثانيتها البنيّة العرفيّة التي تحققها والمراحل التاريخية التي تحددها كما تعينت في فلسفة الدين القرآنية، لنختم البحث بعلاج مسألة الدليل الوجودي أو الميثاق الإسلامي ونظريّة القيم النابتة عنه. (- مهكذا:

1- فسنحلل في الفصل الأول عوائق إدراك الروحانية الإسلامية وعوائق إدراك مبادئها، تحليلا لا

$$
\text { يفصل بينهما إلا منهجيا، بدءا بالأول وختما بالثاني. }
$$

2- ونعالج مسألة النسق الذي تنتظم بحسبه العلوم أدواتٍ وغاياتٍ في المنظار الإسلامي، والتحقيب

$$
\text { التاريخي المحدِّد لمراحل التطوّر الروحي الإنساني. }
$$

3- ثم نختم البحث بتحديد مقومات علم الكلام الإسلامي، كما تعين في الدليل الوجودي ونتائج

$$
\text { هذا الكلام في تحديد نظريّة القيم الإسلامية. }
$$

\section{معيقات إدراك الروحانية الاستخلافيّة ومبادئها}

أولا - المعيقات: ينبغي أن نتخلص من الموقف الفلسفي الخلقي الناتج عن تأثير الفكر الأفلاطوني المسيحي الذي تبيَّن تنافيه مع الإسلام لإخفاق كل محاولات التلفيق التي أقدم عليها غلاة الفكر العربي الإسلامي خلال هضته الأولى، وذلك بحكم تأثير الانطاط الذي أصاب الأفلاطونيّة التوراتيّة المحدثة الهلنستية، فنقبل المنبوذات الخمسة التي تحددت فلسفة الإسلام العميقة بإِباتها لحقيقتها ومنزلتها الوجوديّة

G. W. F. Hegel: Volrlesungen uber die Philosophie der Wwltgeschichte, IV. انظر Band, Die Germanische Welt, Her von. G. Lasson, s. 789-797 Der Mohammedanismus. انظر أبو يعرب المززوقي: "الدليل الوجودي الحلولي"، إسلاميّة المعرفة، العدد الحادي عشر، شتاء 1998. 
الرفيعة: 1- الوجود الشخصي للفرد الإنساني وأبعاده المجردة الأربعة، أعني: 2- الذوق الشخصي، 3والحس الشخصي، 4- والملك الشخصي، 5- والحريّة الشخصية.

وتقبل هذه الأبعاد في الدنيا والآخرة، لعدم الفصل بين الروح والجسس، ولعدم التحقير للثاني، فهو

يبعث مثل الأولى، وهي تذوق الموتَ مثله. بل إن طبيعة العلاقة بين الدنيوي والأخروي في الوجود الإنساني والكوني هي من طبيعة العلاقة نفسها بين الروحي والجسدي في الشخص الإنساني.

كما ينبغي أن نتخلص من الموقف الكلامي الفقهي الناتج عن تأثير الفكر الأرسطي التوراتي الذي تبين تنافيه مع الإسلام في المحاولات نفسها التي أقدم عليها الفكر العربي الإسلامي في غضته الأولى، بحكم الانخطاط الذي أصاب الأفلاطونيّة التوراتية المحدثة الهلنسيّة، فنقبل المنبوذات الخمسة التي تتحدد فلسفة الإسلام بإثباها لحقيقتها ومنزلتها الوجوديّة الرفعية وهي: 1- الوجود الكلي (للعالم: الطبيعة والتاريخ) وأبعاده المجردة الأربعة؛ أعني: 2- الرياضيات أو جماع علوم الطبيعة؛ 3- وعلم المنطبق؛ 4- والسياسيات أو جماع

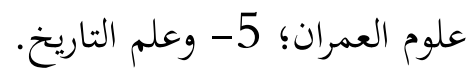

وغاية هذين الضربين من الأسس هي إحياء علم العلوم أو علم التوحيد، لكونه يشمل المنبوذات العشرة شمولا فلسفيا علميا، وشمولا دينيا صوفيا، يوِّدّد بينهما النسق الإسلامي الذي يصالح بينهما مصالحة تتجاوز تنافيهما الذي لا مسوّغ له عدا نظريات عرجاء سنعالج بعضها في هذه المحاولة. ويوجد توازٍ بين المستويين الشخصي والعام وبعديْ علم التوحيد. فالوجود الشخصي بأبعاده الخمسة يوازي الوجودَ الكلي بأبعاده الخسمية. وعلم التوحيد أو نظرية الوجود الدينية في بعدها الذي تغلب عليه المنبوذات الفلسفية يوازي عِلْمها في بعدها الذي تغلب عليه المنبوذات الكلامية. لكن سيطرة المقابلة بين هذين البعدين في الفكر الفلسفي العلمي وفي الفكر الديني الصوفي جعلتا الفكر السائد في الحضارة العربية الإسلامية فكرا يتبنَّ هذا الفصام، فيتألف من بعدين كلاهما أعرج: - - فالفكر الفلسفي العلمي أعرج، لكون منبوذاته (الوجود الشخصي وأبعاده الأربعة) جعلت مقبولاته (الوجود الكلي وأبعاده الأربعة) تصبح أوهاما لا أثر لها في الوجود التاريخي الإنساني. 
- - موالفكر الديني الصوفي أعرج، لكون منبوذاته (الوجود الكلي وأبعاده الأربعة) جعلت مقبولاته (الوجود الشخصي وأبعاده الأربعة) تصبح ثَثَثَة في الحياة الباطنية لا حول لها ولا قوة.

فلا سيادةً للإنسان على الوجود الطبيعي والعمراين دون العلوم التي موضوعاتما منبوذات الفكر الديني الصوفي الأعرج، ولا معنى للوجود الإنساني ولسيادته على الكون والعمران ما لم يكن له الأبعاد التي تَعدّها الفلسفة والعلم (الأعرجان) من المنبوذات. ولحسن الحظ فتطور الفكر الإنساني انتهى إلى إدراك أهمية البعدين، ومن تَمَّهَ فهو مستعدُُّ لفهم الروحانيّة المورِّدة بينهما، أعني جوهرَ الروحانيّة التي يستند إليها الإسلام. وذلك هو شرط استئناف الفكر الإسلامي الحي: لا بدّ من تأسيس الفكر الإسلامي الجديد على هذه الأبعاد العشرة وعلومها المضاعفة للوجود الإنساني السوي.

ثانيا - المبادئ: وتتعلق المبادئ بتحديد النظريات الآتية: أولا: نظرية العلم، ثانيا: نظرية الوجود بما هو موضوع نظري، ثالثا: نظرية العمل، رابعا: نظرية القيمة بما هي موضوع عملي، وأخيرا: نظريّة الأساس/الأصل التي تستند إليها جميع هذه النظريات وموضوعاةًا، أعني علم التوحيد الإسلامي.

1- فالنظر ليس هو إلاّ الاجتهاد النظري (الذي هو مبرًّ من تبعات الخطأ عند توافر شروط المجتهد فيمن يقوم به)، أعني مجرد خطة إنشائيّة تخيليّة وظيفتها تنظيم الحبرة الحاصلة لإبداع الخبرة الممكنة بفضل آليات استخراج الممكن من الحاصل؛ إنه:

- أفضل تحديد للعناصر التي من المفيد عدّها عناصر مقوِمة للحاصل. - البحث عما يمكن أن تكون هذه العناصر نتائج له. - البحث عما يمكن أن يكون نتائج لهذه العناصر. - افتراض ما يمكن أن يدخِل عليها عقلانية أفضل، أعني أجمل وأنجع. 
وكل هذه الأبعاد تتكرر عند السعي إلى إخصابها بالمطابقة مع المجال الذي تعَدّ تلك الخطة التخيّلية أفضلَ "تفسير" مؤقت له. فلسمّ هذا: رياضيات. وإذا عاد النظر على نفسه ليجعل منها لذاتما موضوع علم سميّناه: منطقا.

2- وموضوع النظر ليس إلاّ مستوى وجوديا تصوريا يفرض قائما بذاته خارج هذه الخطة وحاصلا قبلها، لئلا تكون الخطة بجرد رواية خيالية. وهذا الموضوع، مثل خطته، ليه الأبعاد نفسها أعني: هو وشروطه ونتائجه ومتمماته الافتراضية، علما بأنه هو الآخر افتراضي، لكنها دونه كثافة واقعية. فلنسمّم هذا: طبيعيات (بجال فرضيّة الضرورة اللازمة للنظر شرط وجود)، ولنسمّ كل المجالات التطبيقيّة التي هي من توابع الطبيعيات تقنيات مادية، فيكون حاصل النظر وموضوعه: المنطق، والرياضيات، والطبيعيات، والتقنيات المادية. ويوحِد بين هذه الموضوعات الوجود الطبيعي وجودا قائما بذاته ومتعاليا عليها تعاليَ غاية لا يدركها الاجتهاد إدراكا مطلقا:

3- أما لعمل فهو الاجتهاد العملي، اعني مجردَ خطة إنشائيّ' تخيليّة وظيفتها تنظيم استعمال النظر علما بالوسائل والغايات وظروف التحقيق وميسِراته وعوائقه الماديّة والمعنوية، مثل عطالة التقاليد والمصالح المتضاربة في ظرف ظرف من ظروف المجتمعات الإنسانية. لذلك فسنسمي هذا الأمر من الآن: سياسات. وإذا عاد هذا على ذاته ليجعل منها موضوع علم لذاتحا، كان ذلك تاريخا.

4- وموضوع العمل ليس إلا مستوى قيميا تصوريا يفرض قائما بذاته خارج الخطة العملية ومكن الحصول حتى لا تكون الخطة مجرد تمنّ، فلنسمِّه: عمرانيات، أعني بجال فرضية الحرية اللازمة للعمل شرط إمكان. وكل المجالات التطبيقّة التي هي من توابع العمرانيات أو الخلقيات فلنسمها: تقنيات رمزية. فيكون حاصل العمل وموضوعل: التاريخ، والسياسات، والعمرانيات، والتقنيات الرمزية. ويوِّحد بين هذه الموضوعات الموضوع الشريعي المتعالي عليها تعاليَ الغاية التي لا تدرك للعلة نفسها الواردة في حالة النظر. ويوحِّد بين التوحيدين، أي بين الوجود الطبيعي والوجود الشريعي، الوجود المخلوق عامة ببعديه النظري الطبيعي والعملي الشريعي بما هو وحدة الآيات الدالة على الفعل الإلهي في العالم والتاريخ فيما هو 
موجه منهما إلى الإنسان. (والمعلوم أنه إذا استعملنا التقنيات المادّية في المجال السياسيّ اعتبرنا الإنسان جسما لا غير فكان الاستعباد والعنف، وإذا استعملنا التقنيات الرمزية في المجال الطبيعي اعتبرنا الطبيعة ذاتَ روحٍِ فكان الدجل والعلم الزائف. وغالبا ما يلتقي هذان الموقفان، إذ في الحالتين نعامل الشيء بخلاف ما تقتضي طبيعته أو ما نعلم منها).

5- أما الوجود المطلق أو الواجب بذاته فنعتقده أساسا/أصلا يقوم عليه كلّ ذلكن وهو من حيث

الوجود موضوع إيمان خالص يمكن تدعيمه بالحجة العقلية دون أن تكون كافية في حصوله. أما الشعور به فمجرد تعبير عن موقف وجوديٍّ يحدّد نسب القيوميّة أو الكثافة الوجوديّة بين الكائنات، أو نصيبها من شهود الوجود الذي هو جوهر قيامها. وفي آياته يلتقي الإمكان والوجود والوجوب والامتناع -التي هي كلها بالغير - مواقفَ وجوديّة لا حقائق فعليّة إلاّ في المستوى الإيماني. وهذا الأساس/ الأصل هو غاية التجربتين الفلسفيّة العلمية والدينية الصوفية، وهو خاصة موضوع العاطفة الدينية والذائقة الجمالية والتجربة الصوفية. إنه، بصورة عامة، عن الموضع المطلق لكل شعور بالإطلاق وبالبقاء وبالوجود. ولنسمّ كلَّ تعبير عن هذا المستوى، أيا كان شكله (علميا تعليليا أو عمليا تأويليا)، شعرا أو تعبيرا عن الإدراك الجمالي الديني للوجود وما ينتج عنه من تصورات للعالم تحدد علاقات القوة والصراع بين البشر أرادا وجماعات. وهو مستوى من الوجود ليس لنا به أدنى علم، وكل ما نزعم حوله بجرد إيمان وعاطفة وجدانيّة لا غير. وما نحدسه منه إنما

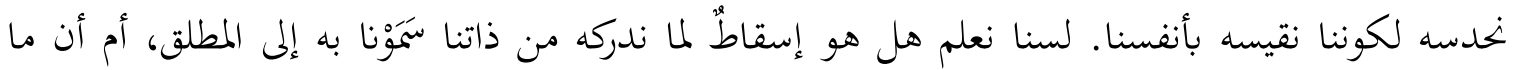
نعلمه من ذاتنا بجرد إسقاط محدود من ذاتنا بصفتها، هي الأخرى، بجرد إسقاط محدود إلى ما لا ذهاية من صورتنا عن الوجود المطلق لا يمكن أن نصفه بأي من الجهات بالمعنى التقليدي (الإمكان والوجوب والامتناع)، لأنه هو الإطلاق أو الذات المطلقة التي لا يحدها إلا ذاتا؛ أعني، بلغة كلامية، الصفات الخمس التي يتصف بها الله بجموعة في وحدة الذات: الوجود والحياة والعلم والقدرة والإرادة. أما الجهات فلا يتصف بها إلا الوجود النسبي أو المخلوق، وهي: 1 و2- الجهتان الموجبتان، اعني الوجوب بالغير 
والراجحيّة بالغير، 3 و4- الجهتان السالبتان، أعني الامتناع بالغير والمرجوحيّة بالغير. ثم الوجود الممكن أو المباح الذي تعد الجهات جهاتٍ له: إنه جنس الوجود النسبي المخلوق.

ويككن أن نعرِّف جنسئ الوجود (المطلق الخالق والنسبي المخلوق) بالصورة الآتية، استعمالا لنظرية ابن سينا في الكلي مع تعديلات، لأن ما هو "لا بشرط"، لا يمكن أن يكون متعددا، فينطبق على الوجود الماهوي المتعدد كما يتصور ابن سينا، إذ عندئذٍ يكون مشروطا بكونه غيرَ غيرِه، فيكون العدم قد دخله

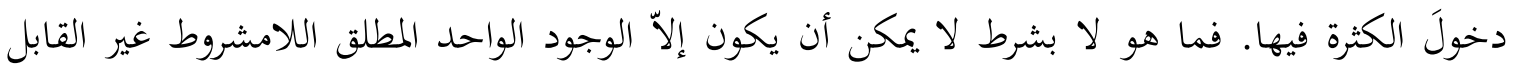
للوصف.4

أولا: الوجود المطلق هو اللامشروط الموجب، وهو الوجود لا بشرط شيء. إنه الوحدة المطلقة التي

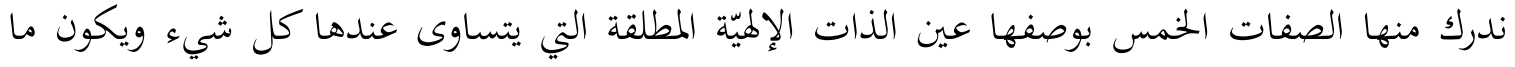

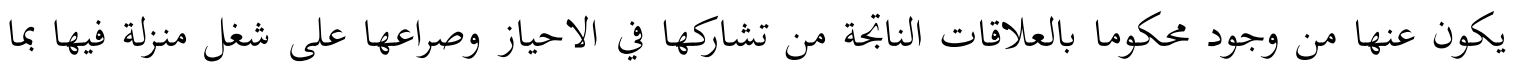

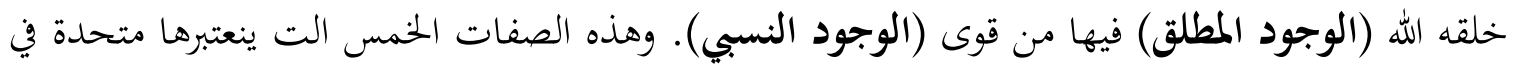
ذاته إنما نستنجها من الأصول التي تتوقف عندها سلسلة الظاهرات عندما نصنفها تصنيفا يحافظ على

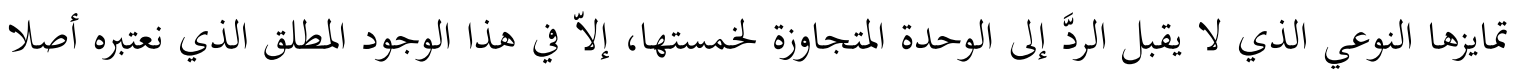

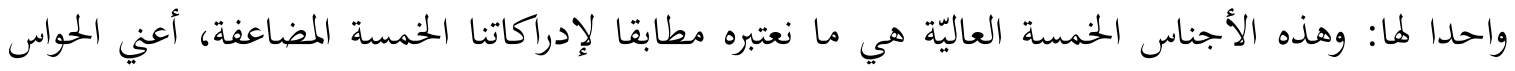

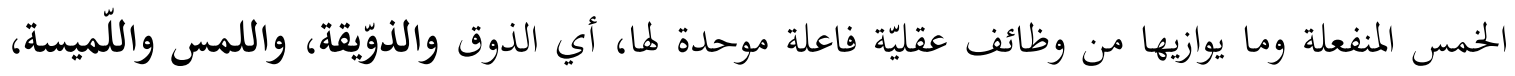

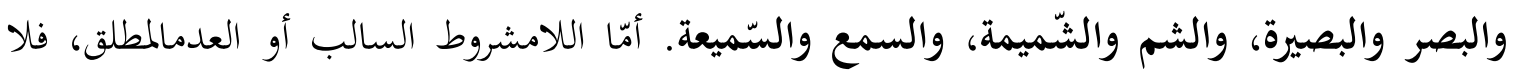

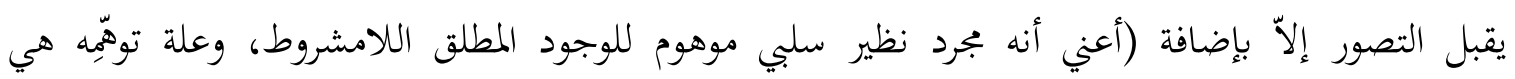

33

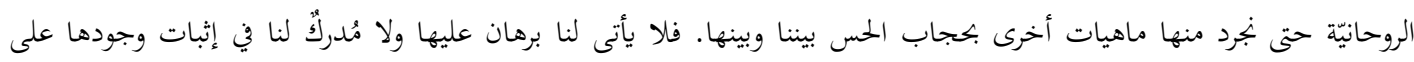

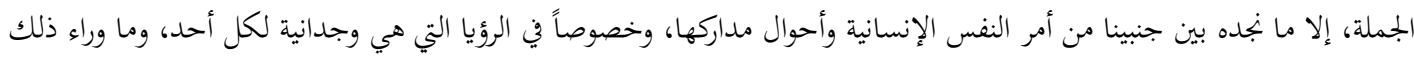

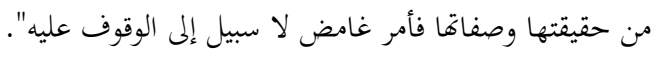
انظر: ابن سينا: إلميات الشفاء، تحقيق الأب جورج قنواتي وسعيد زايد، القاهرة: الهيئة العامة للمطابع الأميرية، 1960، ص200- 
الذهاب إلى الحد الأدنى في السلب نظيرَ الذهاب إلى الحد الأقصى في الإيجاب، وسنرى لم يكون الذهاب الأول ضرويا والثاني متنعا).

$$
\text { ثانيا: الوجود النسبي، هو الوجود المشروط الموجب أو السالب، وهو ضربان: }
$$

الوجود بشرط شيء: وهو نوعان: الواجب بالغير، او الوجود القاهر بإطلاق او براحجية لكون علته الموجدة الواسطة (طبيعته) حلقة بتعلها تكون غالبة إما بإطلاق أو براجحية. وهذا الوجود بشرط هو الموجود المشروط بانتفاء المانع، ولا يكون ذلكإلا بالأمر الإلهي أو الفعل الموجب: الإبداع والرازقية، شرطا المبدعيّة

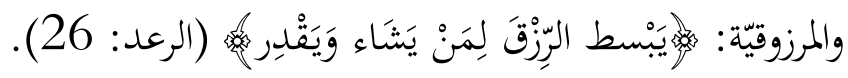

الوجود بشرط لا شيء: وهونوعن: الممتنع بالغير، أو الوجود المقهور بإطلاق أو بمرجوحية، لكون العلة الموجدة خلقت خلقة بتعلها تكون مغلوبة بإطلاق أو براجحية. وهو الوجود المشروط بالنهي الإلهي أو

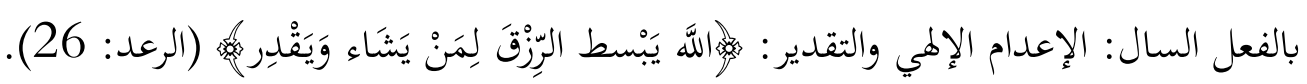

أما الفهم الفلسفي التقليدي للجهات فهو غير متناسق. ذلك أن الإمكان المطلق ليس إلاّ تساويي القوى المتقابلة أو تراجحها، فتنتهي إلى عدم رجحان أيٍّ منها. وهو إذا مشروط بما يشبه الحريّة أو بالإرادات المتقابلة المتصارعة. فإذا فرضنا هذا الشرط موجودا، بات من الواجب أن نفترض متقدما عليه شرطا أعمق، هو التقابل بين حصول أي منها بإطلاق أيا كان وعدم الحصول بإطلاق، فيكون الخيار بين الوجود والعدم. لكن التراجح بين الوجود والعدم الذي كان يعرِّف به الفلاسفة الإمكانَ مفهومٌ متناقض. فكيف نفترض العدم أمرا له من الطاقة القياميّة ما يجعله عديلا للوجود الممكن يقابله؟ كيف يكون العدم ممكنا عندما يكون الوجود ممكنا؟ فما هو وجود ممكن قبل نقلته من الإمكان إلى الحصول يكون فوق العدم، وإن كان دون الوجود الحاصل، فكيف يكون العدم الممكن؟ هل يكون دون العدم الحاصل؟ فيصبح العدم عدمين؟ العدم

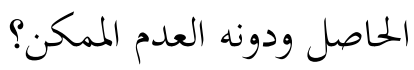

وهذا التراجح المطلق، إذا لم يكن حصيلة عمياء لصراع آلة متعددة هي هي هذه القوى المتراجحة ولا ينبغي له لأن بقاء الصراع بما هو بقاء بكون مبدأ فوق المتصارعين فيكون إله الآلة المتصارعة أو الدهر، 
وتلك هي الوحدانيّة العمياء فاقدة الوعي والقصد- لا يتحقق إلاّ لإرادة الخالقة ذات القصد العاقل، الإرادة الإلهيّة التي تحقق شروط التعايش بين المخلوقات شرطا متقدما لقيامها، لا حصيلة تالية عن فوضى صراعاتا. وهي بتعل هذا التعايش في حركية دائبة من المدِّ والجزز لا يكون فيها التراجح المطلق إلاّ حالة نظريّة خالصة، لو حصلت لتوقف الوجود المخلوق عن البقاء الحي، ولانتهينا إلى الجمود والموت. بل إن الوجوب نفسه لا معنى لا له إلا إذا اعتبرناه الممكنَ الذي لا نتصور عدَمَه ممكنا. وهو إذا حالة من الرجحان المطلق، أعني ما لمان ينفي المرجوحية المطلقة أو المعدوم، ولا يتم ذلك إلاّ لمراد القديم. ذلك ن الممتنع المطلق هو المرجوح المطلق، أعني المعدوم أو غير المراد لله.

وإذا فالوجود المطلق أو اللامشروط الموجب بالذات لا يقابله العدم المطلق أو اللامشروط السالب، إذ لا وجود إلاّ للعدم المسلوب المشروط بمنع الغير إياه من الوجود، ثم الوجوب والراجحيّة بالغير والامتناع والمرجوجيّة بالغير، ولا شيء من الموجودات بواجب بذاته إلاّ القديم الموجب أو الوجود المطلق. أما الممتنع بذاته فلا معنى له، لأه لو كان ذا ذاتٍ لكان على الأقل ذا وجود تصوري فلا يكون متتنعا، وهو خلْفِ. إنا العدم المطلق بجرد إطلاق للفرق بين الخالق والمخلوق ذهابا إلى الغياية في نفي قيام المخلوق وإثبات قيام الخالق. لكن المخلوق المنفيَ يحافَظ عليه قبالةً الخالق خانة فارغة وكأنه بالقوة كل أفال الخالق قائمة في وسط حاو هو منها بالفعل خلاء وبالقوة ملاء. وذلك هو مفهوم المادة الأولى كما تصوره أرسطو عندما رفض مفهوم العدم الأفلاطوني، 5 وكما فهمه الاشاعرة في رفضهم لشيءيّة المعدوم بالمعنى البهشمي.6 وهو عينه مفهوم المادة اللابينتسي قبالة الامتداد الديكارتي.7 وهو عينه ما أطلقنا علهي اسم الإمكان المخلوق، شريطة

انظر: أرسطو: الطبيعة، ترجمة إسحق بن حنين، 192.9II 31-5: "فإنا نحن نقول غن الهيولي والعدم متغايران وإن أحدهما -وهو

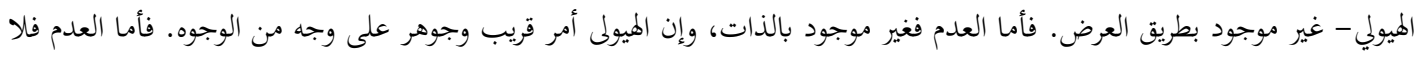

بتة"، ص272-73.

Max Horten: "Die Modus Theorie des Abu Haschim”, Ein Beitrag zur ) 6

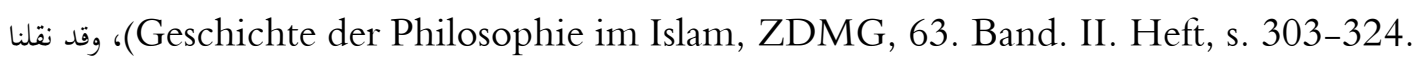
هذا البحث مترجماً إلى العربيّة بعنوان نظرية ابي هاشم الجبائي في الأحوال. وقد نشر في مجلة الحياة الثقافية التونسية، عدد ديسمبر .1997

Leibniz: Opuscules Philosophieques, Trad. Schrecker, Vrin, Paris, 1969, P.76-) 7 (78 "Remarques sur la partie generale des principles de Descartes". 
وضعه حادثا بإطلاق، لكون المعدوم ليس بشيء. وهذا الإمكان المخلوق هو الذي ينقسم إلى الجهات الأربع المتفرعة عنه بصفته الجهة الأولى الأصل: الإمكان المخلوق، ثم الراجح بإطلاق أو الواجب، والراجح بإضافة أو المندوب إليه، ثم المرجوح بإطلاق أو الممتنع، والمرجوح بإضافة أو المكروه. وكلها تبقى ممكنة وإلا لامتنع عدم حصل الأول وحصول الأخير في المجال الشريعي قياسا على البجال الطبيعي. فلا يبقى فرق، عندئذة، بي الاختيار والاضطرار.

إن الله هو موجد الموجودات التي ليس منها إلا ما كان واجبا به أو ممتنعا، راجحا به أو مرجوحا. ولا وجود لعدم نسبي كذلك، فلو كان لوجد عدم مطلق يشارك الوجود المطلق في تنظيم العلاقة بين الموجودات النسبية، وما يعَدّ عدما نسبيا ليس هو إلاّ نظام المخلوقات بما هو غيرها إذا اعتبرت واحدا واحدا دون البقية. إنه كون الشيء هو هو، أي ليس غيره من الموجودات التي ينتظم هما الكل: شبه شبكة من الخانات الخخاويّة التي تشغلها الموجودات موجودا موجودا. ومنظومة انظظام الكل هي منظومة أحكام الإرادة الخالقة، وهياذا ليست عدما نسبيا، بل هي وجود نسبي، إذ هي إحدى صفات أفعال الذات، أو الوجود المطلق. والوجود المطلق تصدر عنه كل الجهات التي هي الوجود النسبي بمعانيه الأربعة. إن العدم المطلق لا جهات له، إذ هو غير خالقن اللهم إلاّّ إذا اعتبرنا العدم النسبي هو عينه الوجود النسبي. لكن عندئذٍ يصبح العدم النسبي هو شرط الخلق الإلمي فعلا وتركا. والترك الإلهي نفسه ليس عدما، بل هو إرادة جازمة، إنه وجود موجب. وما يمنعه الله لم يكن حاصلا فيعدمه، إلايّ إذا صيرنا شبكة الخانات الخناوية الوهميّة ضرورة تخضع لها الإرادة الإلهيّة شبيهة بعالم مثلٍ مسلوبة متقدم على الخلق. إنما هذه التصورات بنت قياس الاختيار الإلهي بالاختيار الإنساني بين خيارات متقدمة عليه محتومة، كأن علم لله وإرادته ناقصان نقص علم الإنسان وإرادته 8 المحكومين بمحدودية حياته وقدرته.

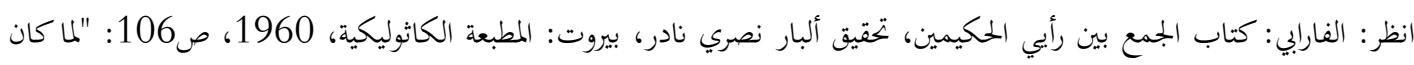

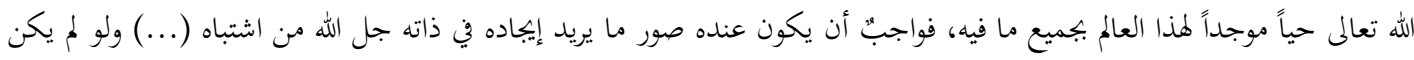

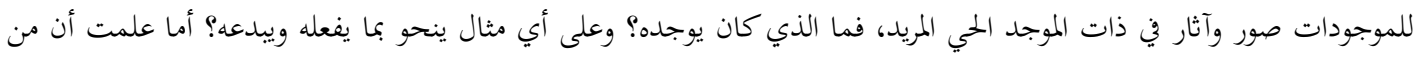

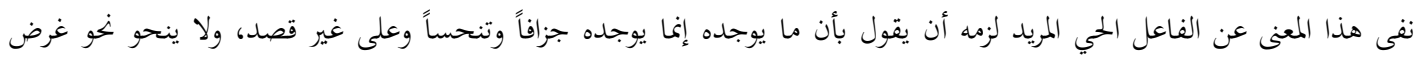
مقصود بإرادته. وهذا من أشنع الشناعات". 
أما الممكن أو التعينات الوجوديّة التي يميزها العقل الإنساني بصفتها بجالات فعله النظري والعملي فهي: الوجود العام، أو نظام الموجودات، أو صورة الإرادة الإهيّة الخالقة والآمرة (وإدراكها هو سبيلنا إلى الشهود، وعلمها هو سبيلنا إلى علم التوحيد بعنييه)، والوجود الطبيعي، والوجود العضوي، ووجود الإنسان النفسي، والوجود الاجتماعي (وجملة إدراكاها تتحد في الحس الناطق، وعلومها هي العلوم الأربعة الباقيّة بمعنييها). وأهم مسألة يتعلق بها كل جواب فلسفي في جميع تلك المجالات هيك ما هي الوسائط بين الاجتماعي والنفسي والعضوي والطبيعي والوجودي (أو، إن أخذنا الترتيب تنازليا بحسب الماصدق لا المفهوم، بين الوجودي فالطبيعي فالحيوي فالنفسي فالاجتماعي)؟ وكيف نمر من الوجودي إلى الطبيعي، ومنه إلى الحيوي، ومنه إلى النفسي، ومنه إلى الاجتماعي؟ ثم في الاتحاه المقابل؟

فإذا استطعنا استرقام (فك الأرقام أو الرموز المغلقة) كل مجال منها بوصفه خطابا إلهيا موجُّها إلينا يكون فهمنا للموجَّهِهِ منه إلينا دائما حقيقيا ولا معنى لكونه مطابقا له، إذ الأمر يتعلق بدرجة فهمنا للموجه إلينا وليس بدرجة المطابقة مع الخطاب في ذاته، إذ هو خطاب ليس مقصورا على الإنسان مخاطبا وحيدا، بل هو يتجه إلى كل المخلوقات التي تفهمه كل بحسب ضرب تقبلها إياه. ومعيار درجة الفهم آيتها عقليا

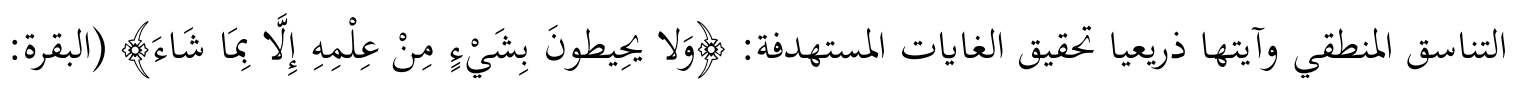
255). أما معيار السعي إلى المطابقة فيقى صالحا في ميدانه، على الرغم من استحالتها. فالمطابقة ليست مطابقة بين الوجود وعلمنا، بل بين علمين محدودين ولكن غير متطابقين لنا عن الخطاب الموجَّه إلينا: الأول هو إدراكاتنا الحسيّة ذات الدرجات والتنوع المحدودين والمتناهيين آلياً، لا ندارجها بين حدَّيْ الممكن الإدراكي للإنسان: حديه الأعلى منه والأدنى (كما في السمع والرؤية مثلا)، على الرغم من السيلان المميز لها. والثاني هو إدراكاتنا العقليّة محدودة الدرجات والتنوع ومتناهيتهما، للتحدد المميز لها منطقيا. وما عدم التناهي وعدم التحدد اللَّذان ينخران علمنا ويمنعان المطابقة إلاّ نتيجةٌٌ للمقايسة بين هذين العلمين اللذين هما غير قابلين للقياس أحدهما بالآخر قياسا مطلقا. والفرق بين ضربيْ الإدراك الذي لنا وما ينتج عنه من عدم تقايس بينهما هو المحرِّك الأساسي لتقدمنا المعريف في التجربة الفلسفية العلمية. وقياسا عليه يكون الفرق بين إدراكاتنا الوجدانيّة وإدراكاتنا العقلية، في التجربة الدينيّة الصوفيّة (الرصد الباطني بلغة السهروردي شريطة حصره تشريعا في الرسل وتعميمه على جميع لبشر فهما للتشريع). فإذا استطعنا ذلك ووجدنا قانونا لترجمة 
ترضينا (دون إطلاق لامتناع التطابق كما ذكرنا في حالتي النظر والعمل، وتلك هي علة الأساس الاجتهادي لكل الحياة الفكرية والخلقيّة في الإسلام) بما تحققه من وصل بين هذه المجالات باعتبارها لغات مختلفة أو آيات مختلفة (أو أنظمة من القوانين: قوانين الوجود العام، والوجود الطبيعي، والوجود العضوي، والوجود النفسي، والوجود العمراني)، أصبح الحلّ ممكنا بالنسبة إلى جلّ الأسرار الفلسفية العلمية والدينيّة الصوفية: فهل هذه المستويات ججرد درجات في امر من طبيعة واحدة، أم هي حجواهر مختلفة؟ وكيف تختلف بعضها عن بعض؟ وكيف تتواصل؟ وما هي طبيعة الوسط الناقل من إحداها إلى أخراها؟

وفي غياب حل هذه المسائل حلا شافيا ينبغي أن نحدد الشروط التي تمكّن من بحاوز المقابلة بين أبعاد العَيْي التي يرفضها الفكر الفلسفي المبتور وأبعاد الكيل التي يرفضها الفكر الديني المجزوء، حتى نتخلص من الفصل المميت للحياة الروحية: الفصل بين التجربتين الدينية الصوفية والفلسفية العلمية. فما الشرط الواجب للجمع غير المتناقض بين نسبة الوجود الحقيقي إلى الشخصي وإلى الكلي معا؟ وما المبادئ الأساسية لفهم نظرية الوجود والمعرفة ونظرية القيمة والعمل والنظرية الجامعة بينهما جمعا منطلقه رفض الفصل بين التجربتين الدينية الصوفية والفلسفية العلمية؟ الجواب عن هذه الأسئلة هو عينه تحديد جوهر الروحانية الإسلامية. ويشترط ذلك شرطا ذا بعدين استندت إليه الرسالة المحمدية، وهو غين مضموها الجوهري: معرين عملي ووجودي قيمي.

1- معرفيا وعمليا: كل مدركاتنا صادقة، على الأقل من حيث هي أمور حاصلة وأحداث واقعة، بصفتها إدراكا نفسيا. ولا يدخلها الكذب أو عدم الصدق إلاّ عند مقارنتها بغيرها من المدركات، سواء تصورناها إدراكاتٍ لشخص آخر أو مدركات خارج كل إدراك. وفي كل الحالات، فالإدراكات بما هي موجودة أمر حقيقي. وما يوصف بعدم الحق هو إذا نسبتها إلى غيرها، اختلافها عن غيرها: إنه إذا علاقة قوة أو تقويم بـ "القياس إلى". وذلك هو سر التسلط في المجتمع الإنساني: التسلط النظري عند أصحاب الميتافيزيقا الإطلاقيّة والتسلط العملي عند أصحاب "الميتا أخلاق" الإطلاقية. وكلا التسلطين يفسر العنف الذي يعانيه العالم الإسلامي عند الحاكمين باسم الأول والمعارضين باسم الثاني. فكل معارفنا الساذجة أو العلمية اجتهادات، إفا مجرد صياغات رمزية نسبية بإطلاق نحاول بها أن نعبر عن إحساسنا بالوجود المطلق 
أو عن الشهود. وهذا التعبير هو الآخر إيجاد لموجود هو الرموز التي نعبر بها والتي تنضم بعد إيجادها إلى دائرة الموجودات فتصبح هي الأخرى موضوعات للمعرفة، وهكذا لا إلى غاية. وكلا الإطلاقين يؤسس للسلطان الزماني أو سلطان الوجهاء (العلمانية: أو سلطان "المافية" المسيطرة بواسطة إطلاق ما هو بالطبع لا يكون إلاّ نسبيا، العلوم النظريّة وتطبيقاها)، والسطان الروحاني أو سلطان الوسطاء (الأصلانية: أو سلطان "المافية" المسيطرة بواسطة إطلاق ما هو بالطبع لا يكون إلا نسبيا، العلوم العمليّة وتطبيقاتا)، هذين السلطانين المطلقين اللذين جاء الإسلام برفضهما ودحض أسسهما (ضري العلوم المطلقين). فليس الإجماع أساسا إلا لكونه إجماع المجتهدين الذين لا يعصمهم شيء عن الخطأ، والذين هم مبرأون من الذنب عند الخطأ لتوافر الشروط التي يقتضيها الاجتهاد بحسب ما هو ممكن للإنسان، فلا يمكن إذا أن يصبحوا سلطانا روحيا معصوما. إنما شأن إجماعهم شأن إجماع العلماء في أي علم من العلوم الدنيويّة مثل إجماع العلماء في توصيف الظاهرات الطبيعيّة أو الاجتماعية. وذلك هو العلم الوحيد الممكن للإنسان إذا لم يكن مؤيَّدا بالوحي، أعني العلم النسبي الاجتهادي. تلك هي ميزة الإسلام الجوهرية، وتلك هي دلالة ختم الوحي وإزالة الكنسية.

فإذا وضعنا معيارا يعلو على الجميع واعتبرناه غير معلوم لمم لتعاليه عليهم (علم الله المطلق) كان لدينا نفي كلا الإطلاقين الشكّاكي والوثوقي، وما يهم هو القصد: فكل الإدراكات حقيقة بقيام وجودها، وهي صادقة بصدق قصدها. وصدق القصد لا يعمله إلا الله، وربما صاحبه إذا شاء الله. أما "القياس إلى"، فهو أمر ذريعي وبجرد وسيلة يعيايَر بها إدراك الإنسان، لا من حيث قصده، بل من حيث جدواه ونفعه. وعندئذٍ فإن الإنسان يصبح وسيلة لغير المطلق، فلا يبقى كما ينبغي له أن يكون، أعني مدركا للمطلق عابدا إياه. 2- وجوديا قيميا: الإميان بوجود المطلق علما بوجوده دون تحديدٍ لطبيعته وكيفيات ذاته يؤدي إلى أن كل الموجودات بالقياس إليه متساوية القيمة الوجودية أو الكثافة الوجودية، إذ بجرد وجودها يعني أها ليست عبثا وأها مسنهمة في شهوده. فلو أخذنا شيئين ورتبناهما في سلسلة مطلقة الطرفين، وليكن هذا الإطلاق كمِّيا مثلا، فإن إغفال الطرفين المطلقين يجعل المقارنة بينهما ممكنة: شرطا في المقتضيات الضرورية للحياة الدنيا، والتنبه إلى الطرفين يلغيها فيجعل الجميع حائزين على القيمة الوجودية نفسها، إذ بجرد كون الواحد منهم موجودا يكفي دليلا على جدارته الوجوديّة وحقه في البقاء، مثل جميع الموجودات الأخرى. وفي هذا 
السلّم المطلق لا تقاس الموجودات إلاّ بالقصد في التوجه إلى طرفي المطلق فيكون السلَّم غير ملغ للسلْم. وهذا القصد/ السعي منزلة وجودية، وهو عين الإرادة الوجودية التي قد تكون قوة طبيعية فقط في الكائنات غير العاقلة مع إضافة إرادة خلقية في الكائنات العاقلة: وتحديد المنزلة الوجودية هذا بصفتها قصدا/سعيا يخلصنا

$$
\text { من التقابل السطحي بين الضرورة والحرية. }
$$

فالضرورة هي التلاقي بين ما يقتضيه نظام السلّم الحاصل فعلا بين القطبين اللامتناهيين (وهو دائما ججهول الذات والصفات، ولو كان وحده لآل إلى نفي السلم وإلى الحرب الدائمة، لأن التوازن بين الضرورات ليس باقيا إلاّ بالاختلال بينها مما يهوله إلى لعنة المراوحة جيئة وذهابا بين قطبي الصراع). ولهذا الحاصلِ دائما بعدان في صيرورة دائبة: بعد طبيعي وبعد عماني في صيرورقما التاريخية الدائبة مع طيفها النفسي وصيرورته. والمقدار من القصد/السعي هو الإرادة الوجوديّة التي تتعين في الأشخاص شخصا شخصا (وهو كذلك جهول الذات والصفات دائما)، وله كذلك بعدان: طبيعي، أو الزاد الفطري، وعمراني أو الحصيلة النفسية للتربية في مجتمع مجتمع.

والحرية هي الوعي الصادق بصدق القصد الساعي: إها إذا الجههد المتمثل في التحرر من القياس إلى غير شرط الطرفين وجودهما وإدراكهما، أو الوعي بوجودهما، أي عبادة الله وحده، والتخلص من الأوثان بتخليص القصد/السعي من جميع الأغراض غير وجه الله. وهذا أيضا مضاعف: الوعي الإنساني العام (تحرر جماعي من الأوثان)، وعمق التجربة الشعورية الشخصية بأعماق الوجود الواردة في نظام السلم والمقدار الشخصي من القصد السعي (تحرر فردي من الأوثان).

الحريّة الوحيدة الممكنة للإنسان هي إذا الإيمان بالله، أو التحرر من الأوثان. المطلق الوحيد الممكن للإنسان هو الإيمان أو التحرر الناتج عن الإيمان بالمطلق: وذلك هو الشهود، أو كون الإنسان ذا شعور ووعي. وبهذا المعنى فإن جميع الأوثان ليست إلا قصورا في إدراك هذا المطلق، ومن تَنَّهَ فهي شرك أو تحرر منقوص: إفا الغفلة، أو السِينَة والنوم الذي لا يأخذ الحيَّ القيوم. ولذه الإشكالية وجهان في تاريخ الفكر العربي الإسلامي خاصة والإنساني عامة: 
الأول: كيف تمت الملاءمة بين الكلّي والشخصي في الفكرين الفلسفي والديني، أي بين التجربتين

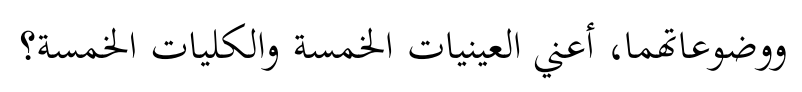

والثاني: كيف أمكن نفي الإطلاق والعصمة مع الإبقاء على القدسية في التاريخ الإنسان؟ ولرً يتمحور

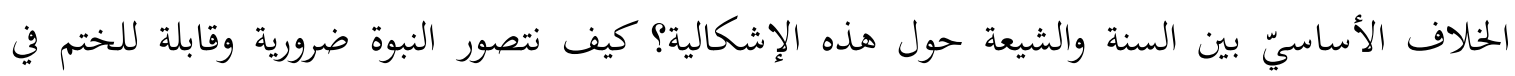

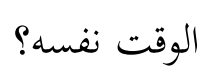

إن المقابلة بين ضري المنبوذات يمكن أن نرجعها إلى تقابل أعمق: فالمنبوذات الدينية الصوفية تعود جميعا إلى ما تطلق عليه الفلسفة صفة التحديد الصوري، والمنبوذات الفلسفية جميعا تعود إلى ما تطلق عليه

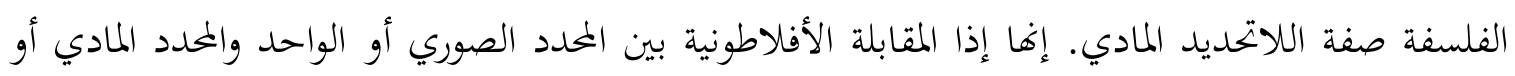

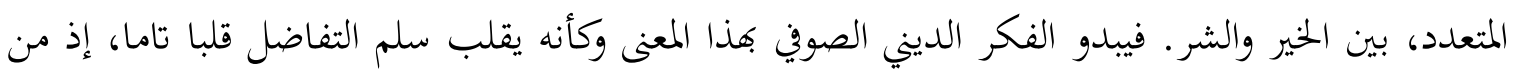
المنظار الديني الصوفي يصبح ما تعتبره الفلسفة والعلم مادة أسمى مما يعتبرانه صورة.

لكن المسألة أعمق من ذلك أيضا. فضربا المنبوذات التي ترجع إلى مكونات الخدد الصوري ومكونات

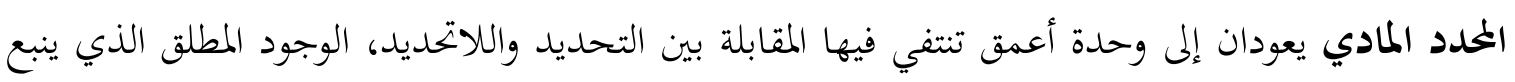
منه الوجهان: وجه التحديد الصوري ووجه اللاتحديد المادي، وهو متقدمّ عليهما كليهما. فالفلاسفة يقابلون بين الثابت الصوري والمتغير المادي، ويعيزون في كل منهما بين الواحد والمتعدد.

فأما الثابت فنوعاه، واحد المتغِِرِ (=المادة الأولى)، ومتعدِّد المتغير (الأعراض المشخصة الطارئة على المتعين في مادة بعينها)، ولا يخالف أفلاطون أرسطو في ذلك. ويعد واحد الثابت وواحد المتغير عندهم وجودا ضروريا، في حين يعتبر متعدد الثابت ومتعدد المتغير عندهم وجودا مككنا، بعضه حاصل وبعضه غير حاصل. ومن الحاصل ما هو ضروري بغيره (الأغراض الذاتيّة

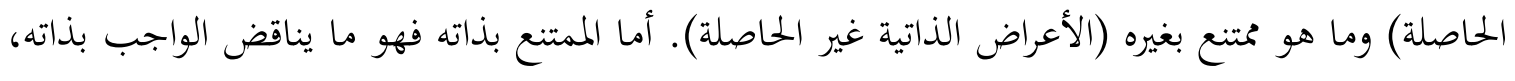

$$
9
$$


أعني ما يتناف مع تناسق الثوابت أو مع تناسق المتغيرات. الواجب عندهم إذا نوعان: صوري ومادي، والممتنع كذلك. ولكل منهما ضربان بحسب ما سبق.

لكنهم يترددون في إرجاع الثابت والمتغير، أو الصورة بدرجتيها والمادة بدرجتيها، إلى مبدأ وجود أصلي واحد. وكذلك الجهات إلى مبدأ جهوي واحد. ذلك أن هذا المبدأ الواحد قد يرد عندهم إلى المبدأ الصوري

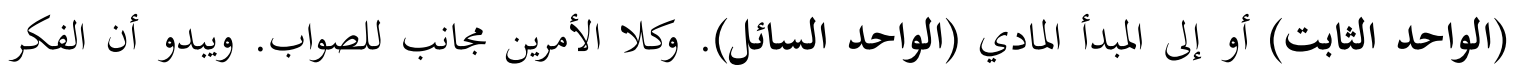
الفلسفي العلمي عامة أميل إلى الرد الأول، وأن الفكر الديني الصوفي عامة أميل إلى الرد الثاني. لذلك فالعلم (بجال التجربة والممارسة الفلسفية) والتصوف (بجال التجربة والممارسة الدينية) ضربان: علم وتصوف أميل إلى الفكر الفلسفي الذي هو ذو ميل "صوري" في الأغلب، وعلم وتصوف أميل إلى الفكر الديني الذي هو ذو

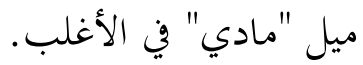

والمتجاوزون للثنائية، أعني المقابلة بين المادة والصورة، وبين الجسم والروح، موجودون في أشرق وجودهم في الغرب، مثل الباقين دوها. وبذلك فإن الزعم بأن الغرب مادي والشرق روحاني فكرة كاذبة، بل لعل العكس هو الأصح، إذا قبلنا بهذه المعايير واعتبرنا المقابلة مقبولة. ولا ينبغي ألاّ نقبل هما فحسب، بل يجب ركب أن نعجب من صبر العقل الإنساني على مثل هذه السخافات. 10 فالمتجاوزان المعلومان هما محِّقا العبور بين التجربتين، إذ لا بتحاوز دون عبور، إفما:

G.W.F. Hegel: Vorlesungen uber die Geschichte der Philosophie, her. Von ) انظر هيجل

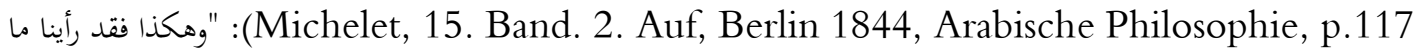

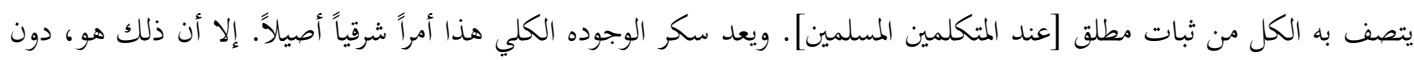

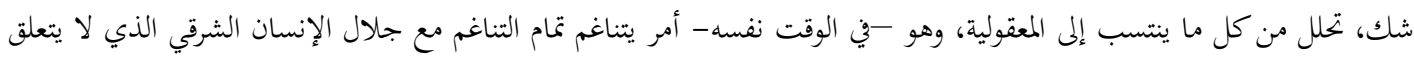

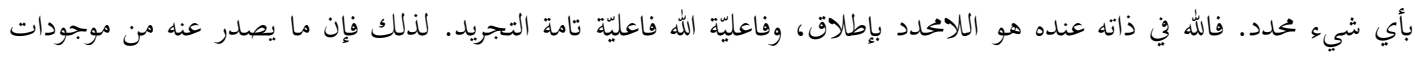

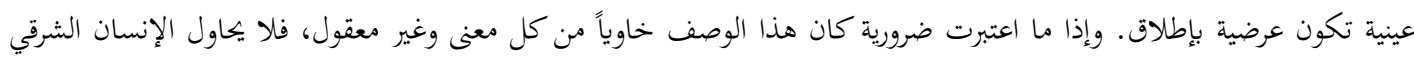

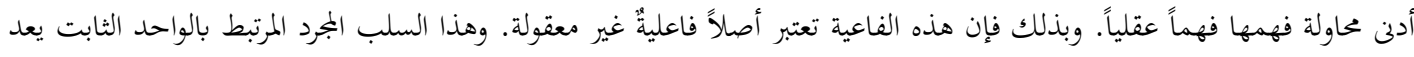

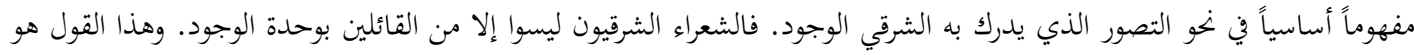

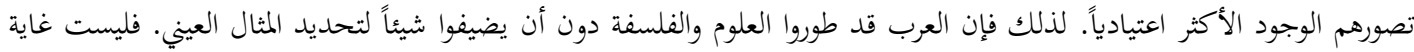

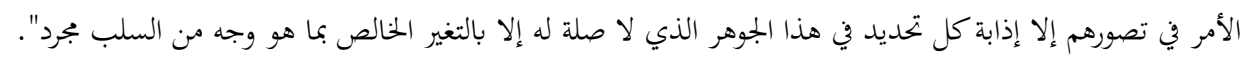


- أفلوطين: تجاوزٌ فلسفي أضفى الطابعَ الديني الصويَ على البعد الوجداني للفلسفة والعلم المستَنْيَيَن للفلسفة والعلم، فصار أقرب إلى أفلاطون وأرسطو غير المرفين منه إلى موسى وعيسى المحرفين. - ومحمد صلى الله عليه وسلم: بحاوزٌ ديني صوفي أضفى الطابع الفلسفي العلمي على البعد الوجداني للدين والتصوف المستثنيين للفلسفة والعلم، فصار أقرب إلى أفلاطون وأرسطو إير الخرفين منه إلى موسى

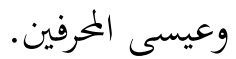

فكان الأول متمِّما لمهمة سقراط بالجواب عن سؤاله الساخر، وكان الثاني متمِمَا لمهمة إبراهيم، بالجواب عن سؤاله الحائر. وبذلك انتهى الفصام بين الفكرين وأساسيهما: التجربتين، الدينيّة الصوفية والفلسفية العلمية. فكان الواحد المتعالي على المقابلة بين الصورة والمادة، وبين الجسم والروج. وكانت الوحدة الشهودية الإنسانية الجامعة بين الرؤية الفلسفية العلمية والرؤية الدينية الصوفية المتلائمتين. لذلك فإنه أصبح، منذ ذلك الوقت، ممتنعا أن نفصل بين الفكرين "الديني - الصوفي" و"الفلسفي - العلمي"، بعد الفلسفة الأفلوطينّة والدين كما نزل به الوحي على محمد عليه السلام، أما ما عداهما من المؤسسين فهم دون الوحدانية المطلقة المتجاوزة لكلا الردين المشوهين للوجود الإلمي. وما يصح على ما حدث بعدهما ينبغي أن يكون مشروطا فيما جرى قبلهما. فالتجربتان، قبلهما، لا يمكن فهمهما إلا بالاتحاه نحو ما آلتا إليه بعدهما بفضل ثورتما الجامعة بين التجربتين الفلسفية العلمية والدينية الصوفية، والعالمين: الطبيعي والشريعي -نظامئ

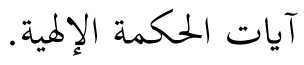

والواقع أن المقابلة الزائفة بني التجربتين هي السر في فصام الفكر الإنساني وانخطاطه. ويمكن أن نحدد أنواع هذا الانططاط تحديدا نسقيا مسبقا بالصورة الآتية:11

علة انحراف العقل الإنساني والانفصام الذي أراد الإسلام تحرير الإنسان منه، هي هذه المقابلات التي يلخصها الانحراف المتمثل في

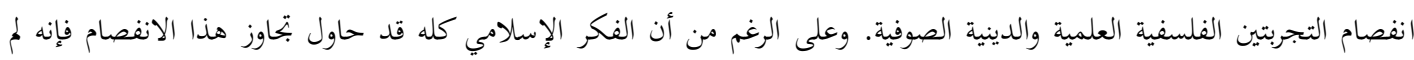

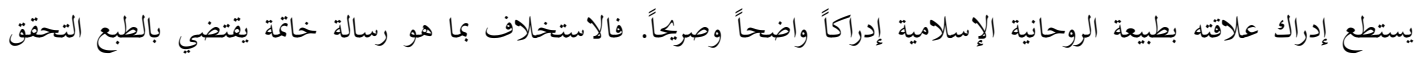

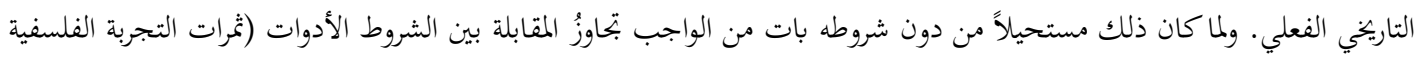

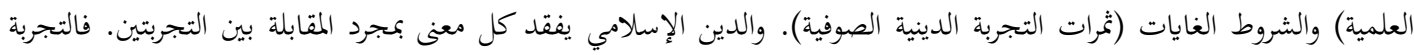

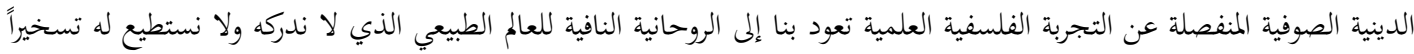
من دون التجربة الفلسفية العلمية. والتجربة الفلسفية العلميّة النافية للتجربة الدينية الصوفية. لذلك كانية التهان القرآن بما هو علم توحيد علم 
الأول: وهو الأساس، إذ منه تبتدئ الانطاطات الأخرى، وإليه تنتهي عند بلوغها غايتها: إنه الفصل بين التجربتين وبين العالمين موضوعيهما. وأخطر وجوه الفصل هي وجوه الوصل الوهمية الإرجاعية المناسبة لوجوه الفصل الإرجاعية.

أولها: بين الدين والفلسفة (عند تخلص كليهما من التجربة الذاتية لكل منهما، أي من التصوف

وثانيها: بين العلم والتصوف (عند تخلص كليهما من الأساس الذاتي لكل منهما، أي من الفلسفة

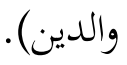

وثالثها: بين الدين والعلم (تعويضا لتجربته الصوفيّة بتجربة الفلسفة العلمية).

ورابعها: بين الفلسفة والتصوف (تعويضا لتجربتها العلميّة بتجربة الدين الصوفية).

وآخرها: كل منها مع نفسه تعويضا للبقية بأوهام تختلقها اختلاقا، استنادا إلى النسقية الوهمية (وأفضل

مثال هو الفلسفة الميجلية الوهمية التي تدعي -وهي هي- أها كل الباقي مغنية عنه؛ وسنفرد النسقية الوهمية وأسسها المغالطية في الفلسفة الهيجلية دراسة خاصة في غير هذا العمل).

الثاني: الدين دون تجربة صوفية، أو الحياة الروحية الخارجية الخاوية والميتة، الحياة التي تتحول إلى نظام من الأوامر والنواهي الخارجية، أي إلى نظام فقهي جامد (وذلك منطلق ثورة الغزالي وسعيه إلى ما أطلق عليه

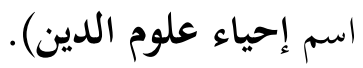
الثالث: التجربة الصوفية دون دين، أو الحياة الروحية الباطنية التي تختمر بغليان فوضى الوهم وغير المتحققة في الوجود الخارجي والترايخي (وتلك هي العلة في الرفض السني للتصوف بمعناه المنحط).

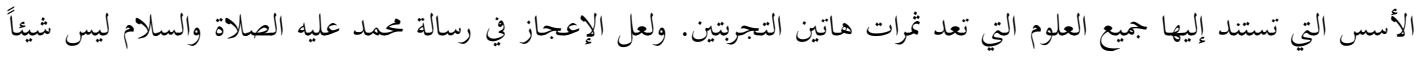

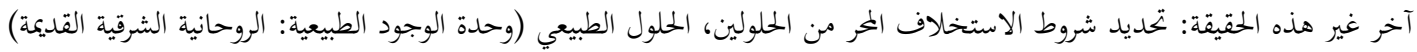
والحلول الربوبي (وحدة الوجود الناسوتية: الروحانية المسيحية الخرفة). 
الرابع: الفلسفة دون بتربة علمية، أو الحياة العقلية الباطنية الخاوية والميتة، الحياة التي تتحول إلى

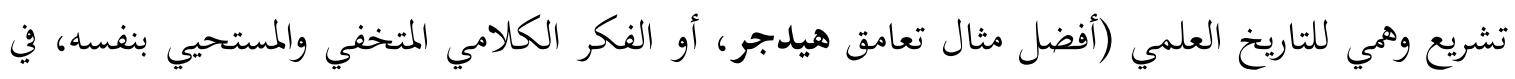
تقعر فلسفي لا غناءً فيه، إلاّ إذا ظننا التلاعب بفقه اللغة وببعض التواردات والخواطر بديلا كافيا عن التجربتين).

الخامس: العلم دون فلسفة، أو الحياة العقلية الخارجية المختمرة غير المتحققة في الوجود العقلي الباطني والنفسي (وقلَّ أن بتد لذلك مثالا، إذ هو يستند دائما إلى فلسفة سالبة، كما هو الشأن في الفلسفات

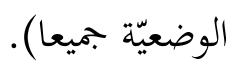

\section{علم التوحيد الاستخلافي وتحقيب التجربة الروحيّة الإنسانيّة}

\section{أولا: التحدي البنيوي للروحانيّة الاستخلافيّة بما هي علوم غايات وأدوات}

لما كان أبعاد الوجود المخلوق هي جوهر الموضوعات التي تدرسها العلوم من منطلقئ التجربتين الفلسفية العلمية والدينية الصوفية، كانت العلوم خمسة أزواج: اثنان نظريان، يؤخذان فلسفيا علميا أو دينيا

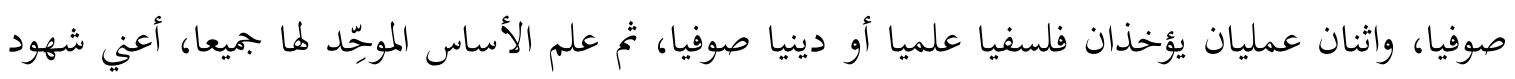
التوحيد فلسفيا علميا أو دينيا صوفيا. تلك هي العلوم العشرة التي يككن استنتاجها من فهم طبيعة الخطاب القرآين بصفته أساس الاستخلاف الإنساني. أما تطبيقات هذه العلوم بدرجتيها فهي، كما قدمنا، علوم

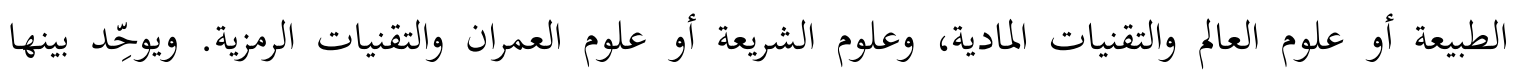
الأساس الموحد للتجربتين، أعني علم الوجود (فلسفيا علميا) أو علم التوحيد (دينيا صوفيا)، ويناظره علم

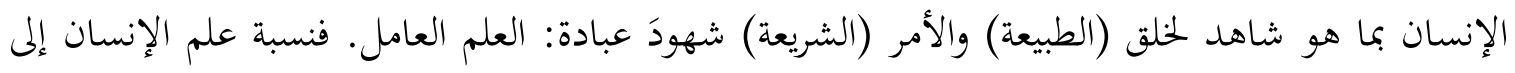
التوحيد، هي إذا نسبة التطبيقات إلى العلوم الأربعة ببعديْ كل منها. وبذلك يتناظر بعدا علم الوجود

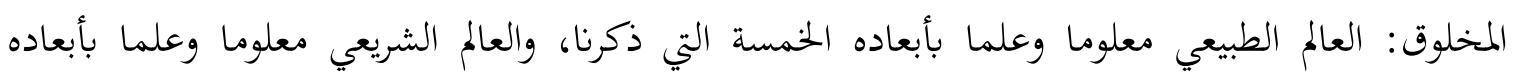
الخمسة كذلك، في علم الوجود أو الفلسفة الأولى فلسفيا -علميا، وفي علم التوحيد أو في العلم الجليل دينيا 
جدول تصنيف العلوم ودلالايّا

\begin{tabular}{|c|c|c|c|}
\hline 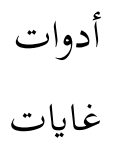 & تعليلي للطبيعة & أب-الفلسفي العلمي & والعلمية 1 علم التوحيد، أو علم العلوم النظرية \\
\hline غايات - أدوات & تعليلي للطبيعة & 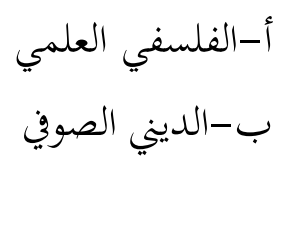 & 2- 2لملم الرياضيات، أو علم التصوير النظري \\
\hline غايات - أدوات & تعليلي للطبيعة & ب-أب-الدلسفي العلمي & 3- المنطق أو علم الرياضيات \\
\hline غايات & تأويليلي للطبيعة العمرانية & أب-الفلسفي العلمي & 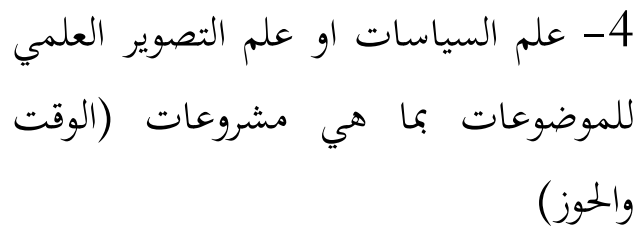 \\
\hline 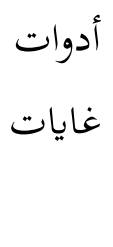 & تأوليلي للطبيعة العمرانية & أب-الفلسفي العلمي & 5- التاريخ أو علم السياسات \\
\hline
\end{tabular}

فالفلسفي العلمي، في كل هذه الحالات، يتعلق بالرمز أو بشكل الوجود الطبيعي الذي نطلق عليه اسم الواجدية والموجودية موضوعا للغة العلمية التعليلية (وهمّه الأول والأخير هو العلوم الأدوات، أعني، أدوات الاستخلاف النظري، أو ادوات تفسير الطبائع والعمل التقني بواسطتها؛ أو تسخير العامل الطبيعي وما في العمران من طبيعي). والديني الصوفي يتعلق بالمرموز أو بمضمون الوجود الشريعي الذي نطلق عليه اسم الشاهدية والمشهودية، موضوعا للغة الشعرية التأويلية (وهمّه الأول والأخير هو العلوم الغايات، أعني غايات الاستخلاف العملي، أو غايات الوجود الإنساني بما هو شاهد للمطلق وعابد للرحمن على علم). والوحدة المتجاوزة لهذا التفرع هي علم التوحيد الذي تؤول إليه هذه العلوم العشرة أو الخمسة المضاعفة: إنه علم القرآن الكريم. وهو ليس بالأمر الزائد عن هذه العلوم العشرة بل هو مبدأ وحدقا. إنها، بصورة أدق، تعيناته وتأولاته الممكنة، إذ إن القرآن الكريم هو التعين النهائي (ختم الرسالة: الوجود الشريعي الخاتم آية 
موازيّة للوجود الطبيعي) للشهود المؤسِّ لها جميعا بوصفها تعبيرا عنه لا يمكن أن تتطابق معه تمامَ المطابقة، مثلما أن الوجود الإنساني الشخصي والجماعي لا يمكن أن يطابق "المشهود -الشاهد- المطلق": الوجود الإلهي الذي ندرك آياته وهي كلام الله تعالى، أو خطابه الموجه إلى مداركنا الحسية ببعديها المشار إليهما

$$
\text { (بمعني الكلام الإلهي: خلقا وأمرا). }
$$

وانطلاقا من هذا التصنيف الدقيق للعلوم ولدلالاتما يمكن إحياء العلوم، إحياء يختلف جوهريا عن إحياء الغزالي، إذ لا داعي للمقابلة بين العلوم الدينية والعلوم غير الدينية، أو بين علوم الآخرة وعلوم الدنيا: فكل العلوم عبادة، ومن تَُّهَ فهي جميعا دينية الجوهر أخرويته. وما يمكن قبول المقابلة فيه بين الديني واللاديني هو التوظيف الممكن للعلوم. ولكن، عندئذٍ، تكون العلوم الدينية، بمعناها عند الغزالي، هي أيضا قابلة للتوظيف الذي ينفي عنها الصفة الدينية، عندما تصبح لغير وجه الله: وتلك هي علة وجود "المافية" الروحية نظيرا "للمافية" المادية. ويتعلق هذا الإحياء بتأسيسها الوجودي وتسويغها القيمي. ولا يكون ذلك سلك إلا بفهم التاريخ الإنساني كله استنادا إلى علم التوحيد القرآي، في معانيه التي ذكرنا، وكما سنحللها تحليلا وجيزا في هذا العمل المخطط لمهمة إحياء العلوم والحضارة الإنسانية من المنظار الإسلامي.

فالرياضيات والمنطق بعدهما الفلسفي العلمي معلوم: إفما علم بنَى الموضوع الطبيعي (وهو بعدّ من كل الموجودات الطبيعية أساسا والتاريخية بحكم دخولها في الأولى بما فيها من طبيعي)، بناه الرياضية المنطقية، أعني علم ما به يصوَّر الموضوع الطبيعي ليصبح قابلا للعلم نظريا، وعلم هذا العلم، بصفتهما بنى متحققة. لكن الرياضيات والمنطق، في بعدها الديني الصوفي، هما الحدس العقلي المدرك للفعالية المبدعة للبعد السابق، عند الإنسان بالنسبة إلى علمه النظري وتطبيقاته، وعند الله بالنسبة إلى ما يفترضه الإنسان علما نظريا يكون الإبداع الإلهي للوجود الطبيعي حاصلا بحسبه، لا بصفته علما يتقدم عليه معلومه، بل هو سابقُ له شرطً

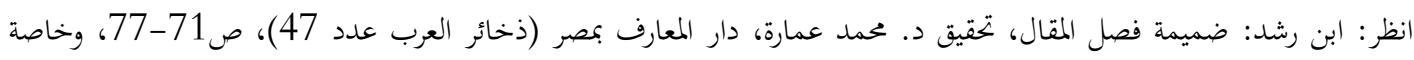

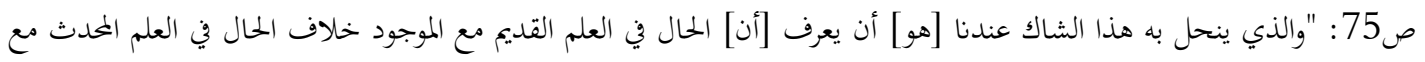

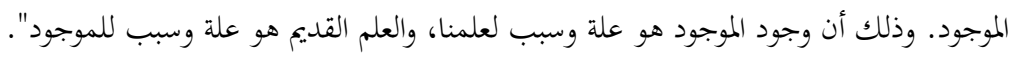


والسياسات والتاريخ بعدهما الفلسفي العلمي معلوم كذلك. إفما علم بنى الموضوع الشريعي (وهو بعدُ من كل الموجودات التاريخية أساسا والطبيعة بحكم دخولها في الأولى بما فهيا من شريعي)، بناه السياسية التاريخية، أعني علم ما به يصوَّر الموضوع الشريعي ليصبح قابلا للعلم عمليا، وعلم هذا العلم، بصفتهما بنية تقبل التحقيق. لكن السياسيات والتاريخ، في بعديهما الديني الصوفي، هما الحدس العقلي المدرك للفاعلية المبدعة للبعد السابق عند الإنسان بالنسبة إلى علميه العملي وتطبيقاته، وعند الله بالنسبة إلى ما يفترضه الإنسان علما عمليا يكون الإبداع الإلهي للوجود الشريعي بحسبه، لا بصفته علما يتقدم عليه معلومه، بل سابق له شرطَ وجود.

ولما كانت العلوم العملية أقربَ إلى بعد العلوم الديني الصوفي، كان أكثر اتصالا بالتجربة الدينية الصوفية منها بالتجربة الفلسفية العلمية. والعكس صحيح بالنسبة إلى العلوم النظرية. لكن الخلاف الحقيقي بين التجربتين يدور حول البعد الثاني من صنفيْ العلوم، وهو إذا ليس مقصورا على السياسة والتاريخ. ومعنى ذلك أن الدين والتصوف لهما علاقةٌ وطيدة بالرياضيات والمنطق، بصفتهما إداعا للبنى لا علم بنى جامدة. الإبداع الرياضي والمنطقي من جنس الإبداع السياسي والتاريخي خارجيا، وهو، باطنيا، من جنس الإبداع الشعري والأسطوري.

والجامع بين هذه الأبعاد هو علم التوحيد الذي لا تنفصل فيه التجربتان الفلسفية العلمية والدينية الصوفية، أعني تحربة بنى الوجود في بعديه الطبيعي والشريعي بصفتها بنى تتحصل، أعني بصفتها النشوء المبدع

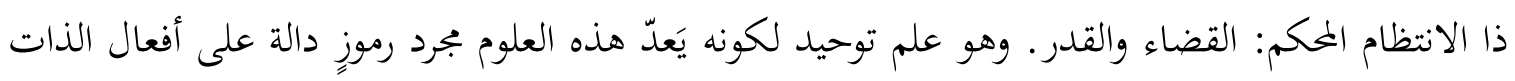
الإلهية المتعالية التي لا ندركها إلاّ بهذه الإشارات والآيات، يعدّها علوما من جنس استرقام الرسائل ذات الكتابة المرقومة لفلٍِّ ألغازها. ويستند ذلك كله إلى ما أشرنا إليه توحيدا بين التجربتين ذهابا من التجربة الفلسفية العلمية إلى التجربية الدينية الصوفية (أفوطين) ومن التجربة الدينية الصوفية إلى التجربة الفلسفية العلمية (محمد صلى الله عليه وسلم): تحقيقا للتوحيد الفعلي وتخلصا من الثنائية. فالمقابلة بين المادة والصورة انتهى أمرها، لتعوضها المقابلة بين الفعل المبدع والمبدَعات الحاصلة، فإذا جعلنا المبدعات موضوعا للمعرفة أعني الموجودية المشهودية، كانت لنا التجربة الفلسفية العلمية والبنى الرياضية المنطقية والسياسية التاريخية 
والوجودية، بما هي بنى حاصلة أو مبدعات. وإذا جعلنا الإبداع نفسه موضوعا للمعرفة أعني الواجدية الشاهدية، كان لنا منه مثالٌ هو الذاتية الفاعلة التي للذات العارفة: وما تلك إلّا بداية التجربة الدينية الصوفية. فلا يَظنَّنَّ أحدُ أخها الغاية فتصبح الذات الإنسانية بديلا من الذات الإلهية، كما هو الشأن في التوحيد الحلولي الذي أتى الإسلام ليخلص الإنسانية منه وليذكر بأنالتوحيد لا يمكن أن يكون إلا استخلافيا

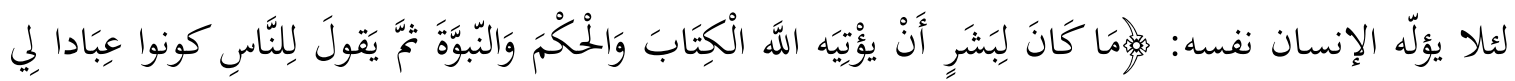

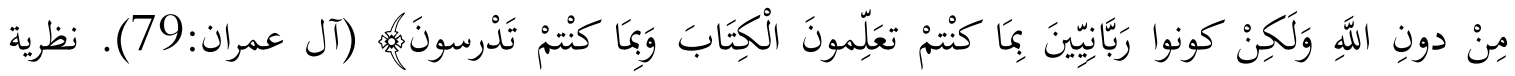
الإبداع الوجودي عن عدم في مقابل الدهرية، ونظرية الإبدع المعريف عن عدم في مقابل الواقعية السطحية، ذلك هو المدلول العميق للمحمدية دينيا صوفيا وللأفلاطونية فلسفيا علميا.

وفي هذا المعنى ينبغي أن نفهم نظرية الجزء الفرد في الفكر الإسلامي. فهو ليس جزءا ماديا كما هو الشأن في المدارس الفلسفية اليونانية القائلة بما يشبهه، وإنما هو "لحظة نقطة وجوجية"، وأنه "مدة امتداد وجودي" أو "بقاء مخلوق" يقوم بفضل إمداد القيومية الإلهية. وهذه المدة هي المنفصل الحاصل عن المتصل المحصِّل أو عن فعل الإبداع الإلهي. المُّدعات منفصلات، وعنصرها الجوهر الفرد أو الجزء الذي لا يتجزَّا. أما الفعل المبدع فهو متصل: إنه فعل الخلق المستمر. وإذا فلا علاقة للجوهر الفرد الإسلامي بالذرة في معناها اليوناني أيا كان المدارس. لا وجود لمادة منفعلة تصورها صورة فاعلة، في نظرية الإبداع الإلهي. لذلك فقد احتاج الفلاسفة القائلون بالصورة والمادة إلى إضافة المبدأ الجامع بينهما دون تحديد لطبيعته (الإله الصانع الأفلاطوني أو الشوق المحاكي الأرسطي، وهما بجهولا الطبيعة ومنافيان لكل مبادئ نسقي صاحبيهما)، وإلى الحصيلة من جمعهما دون فهم لطبيعة الجمع (الجوهر المؤلف الأرسطي أو المزيج الأفلاطوني).

أما عندما نعوض الثنائية بالوحدة، فإن المقابلة تتحول إلى مقابلة بين الفعل المبدع وحصيلته، أي المفعول المبَدع. والفعل غني عما يفعل فيه، كل لحظة سابقة منه تصبح موضوعا للحظة الاحقة منه، فيكون مادة نفسه بعوْدَة لحظٍِه اللاحقة على لحظته السابقة لا إلى فاية. من هنا نفهم علة نسبة الكمال إلى اللامتناهي في الفكر الديني والعكس في الفكر الفلسفي؛ فاللامتناهي هو فعل الإبداع، والمتناهي هو المتبدعات. ليس اللاتناهي صفة للمادة، بل هو صفة للفعل المبدع. وليس التناهي صفة للصورة بل هو 
صفة لآثار فعل الإبداع الحوالي منه، أعني المبدَعات، بعد أن يغادرها النبض الحي من فعل الإبداع. ولو

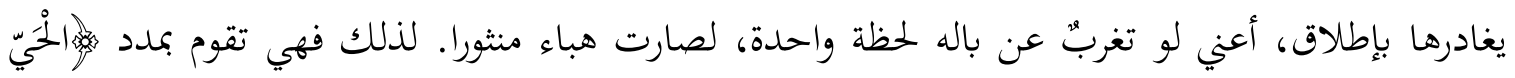

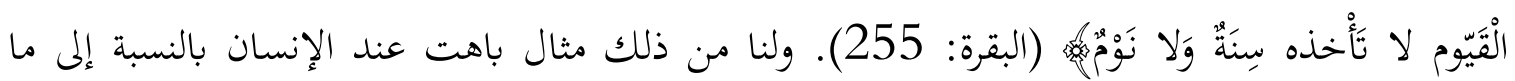
يودعه بين دفتي كتاب: فإذا لم ينفخ فيه الحياة وعي المؤلف نشأة أولى ووعي القارئ نشأة ثانية، لا تكون

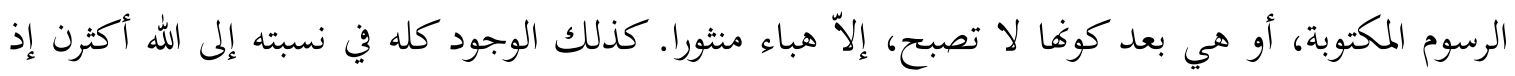
حتى الهباء المنثور فهو ينعدم عند الانفصال عن المدد الإلهي. ويف كل لحظة، فإن القائم في هذه الظروف الجوفاء جديدا يكون، ولا شيء منه يتكرر.

ونخن نقوم مثل كل الموجودات بهذا النفخ الدائم للحياة فينا منذ خلق آدم. وبفضله ننفخ فيما نحييه عندما نوجه إليه فاعلية العقل. النسبة واحدة لكن المتناسبات من طبائع لا نعلم عنها شيئا. ما ننسبه إلى الله ونستمده من القياس إلى أنفسنا إنما هو مجرد مرقاة للشهود، لكن الشهود المقيم للوجود المخلوق ليس بالغا الاتحاد بالمطلق، وإنما هو بالغ التوحد بوهم مه، بعد الكفران به، والزعم بأن الخليفة بات بديلا من المستخلِف، إما لكونه حل فيه (نظريّة الحلول القديمة المسيحية أو الصوفية)، أو للادعاء بأنه مجرد إسقاط نفسي مرضي منه (التأويل الحديث لنظرية الحلول القديم حيث يعد الإنسان خالق الإله بالاستكمال الوهمي لنقائصه الشخصية). 13

وهذه التجربة الثانية لا يمكن الوصول إليه إذا لم نتخلص غهائيا من الزعم بأن التجربة الفلسفية العلمية مكتفية بنفسها وقادرة على ميدِنا بعلم ناجز غير ما يعد به بعض الأدعياء من اكتمال للمعرفة الإنسانية ممكن في الوهم لا غير. هذا الاكتمال الممكن في الوهم يغرينا بغاية ممتنعة على الإنسان، بل إن الظن بأهما مككنة لأحدنا هو عين الوقوع في التأليه الذاتي عند الإنسان. الفلسفة الوحيدة الممكنة هي الربيّة الموجبة

13 Bilbliothek, Reclam Leipzig, 1975, P.23 ) حيث يقول: "يصدر فكر فيورباخ من الأمر الواقع المتمثل في كون

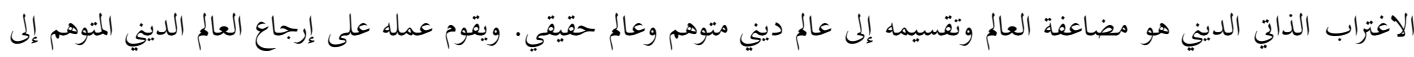

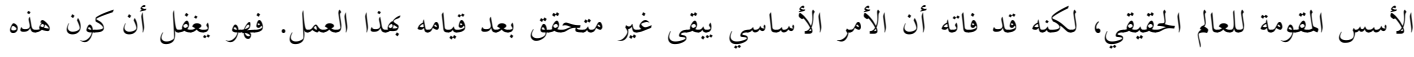

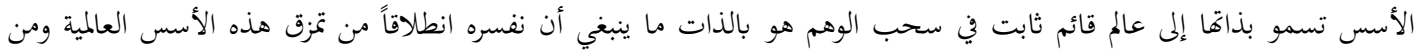


شرطا في الإيمان المؤسِّ للعلم النسبي، أعني الإيمان باختصاص الله بالعلم المحيط. وذلك هو جوهر إسلامية المعرفة التي تخول المسلمين حق قيادة الإنسان الاستخلافيّة بالاستناد إلى الحل الإسلامي للمسألة العلمية.

\section{ثانيا: المراحل التي حققت مضمون الرسالة الحاتمة}

لا يمكن لنا أن نحدد طبيعة القيادة الاستخلافيّة من دون أن ندقق أمرين: الأول: هو منزلة اللغة العربية لا العرب بما هم أحد الشعوب الإسلامية في الدين الإسلامي ومن ثم الحياة الدينية التاريخية لكل المسلمين؛ والثاني: هو منزلة الإسلام في التاريخ الإنساني، كما تحددا في الوعي التاريخي المصاحب للثورة المحمدية.

لا شك أن موقع الأمة العربية ووظيفتها في الملة الإسلامية، مهما كان أهمتهما، ينبغي ألاّ ينقلبا إلى ما يشبه موقع اليهود في العالم المسيحي، لكون الإسلام يرفض عقيدة الشعب المختار ولكونه ضد الاستحواذ على المهمة الروحية، أيا كان صاحب الزعم. لذلك كانت الدعوة والنبوة عامتين لكل الأمم، لكون الاتصال

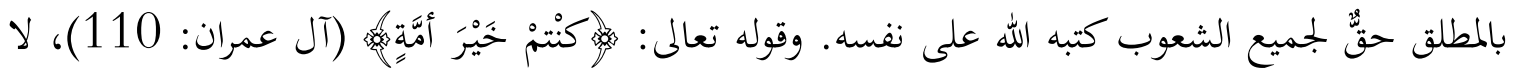
يقصَد بها العرب بالمعنى الجنسي للكلمة، بل المقصود هو كل من يسلم، فلا يكون له معبود سوى الله: كل إنسان متحرر من الأصنام بالمعنى الحقيقي للكلمة، لا بمعناها الرمزي، أو التماثيل. ولن نفهم هذه الثورة الإسلامية إلاّ عندما ندرك دلالات الوعي التاريخي المصاحب لها والمنزلة التي يشغلها الإسلام في تاريخ الحضارة الإنسانية.

ولا شك أن الحضارة العربية، وإن تقدمت على الإسلام، فإها لم تبلغ درجة الإسهام المؤثر في التاريخ الكوني إلاّ بفضل ثورتا الأولى، أعني الإسلام. لذلك فإن تحقيب التاريخ العربي، حتى في امتداده إلى المتقدم على الإسلام، لا يمكن إلاّ أن يُططلق منه بصفته نقطةً البداية، غاية لما تقدم عليه وبداية لما تلاه. فكيف مثَّل المقوِّم الإسلامي عامل التحقيب المؤسس الأول؟ لن نختاج إلى افتراض خطة لتحديد هذا التحقيب، إذ إن الإسلام نفسه يستمد شرعيته من تحقيب متواتر في القرآن تحقيب التاريخ الديني خاصة والتاريخ الإنساني 
وحتى نخلص هذا التحقيب من العناصر غير الجوهرية التي خلطها به الفكر المشوش لبعض أصحاب

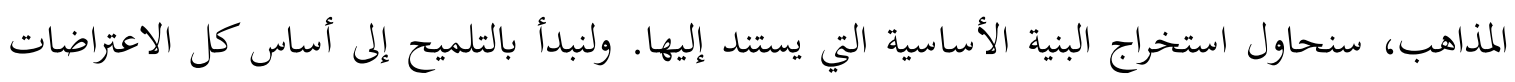
السهلة: فالتصور الإسلامي للتاريخ الوارد ف يالقرآن لا يواصل العرض الاسطوري لتاريخ قبيلة في علاقتها بالغيب، تاريخها الذي أرجع إليه التحريف مضمونَ التوراة. وحتى تخليص التاريخ الإنساني من هذه العلاقة الاستثنائيّة بين الله وشعب مختار كلّ من عداه من البشر عبيد له، على الرغم من منزلته الكبرى في القرآن الكريم، فإنه أمر ثانوي منه. إنما مضمون تحقييه الأهم للتاريخ هو تحقيب لحركة مضاعفة تعد حركة التحريف -التي جزرت عن الإنسانية نهو تاريخ قبيلة أصاها الفصام- أدناهما. ذلك أن الأمر المهم هو حركة التصحيح، حركة المد التي أسست إنسانيّة الشهود الفاعل في التاريخ، بحيث لم ييق الدين بجرد تعبد أعزل، بل هو جهادٌ فعليُّ في التاريخ الجاري حقيقة في الوجود الدنيوي الإنساني من أجل القيم التي نحدد مضموفا في الفصل الثالث والأخير من هذه المحاولة: وذلك في المستويين الروحي والرمزي (مضمون الأقاويل الدينية العقدي النظري) والتاريخي الواقعي (تحقيق مضمون تلك الأقاويل الدينيّة في المستوى العملي). فأما في المستوى الأول، فإن التحقيب يتعلق بتاريخ المضمون الموجب لتوالي الرسالات التأسيسية والتصحيحية مع عرض لتحريفاتما قصده الاعتبار. وأما في المستوى الثاني، فيتعلق التحقيب بتاريخ إرث الأرض وتمكين المؤمنين من السيادة على التاريخ الكوني. مضمون القرآن الجوهري هو إذا هذا التحقيب المستند إلى تحديد آيات الفعل الإلهي الخمس:

1- نظام النفس الإنسانية، 2- النظام الطبيعي أو العالم، 3- النظام الشريعي أو العمران، 4- نظام الرسالات الدينيّ كما تعين في أولاها بالذات وأخارها بالزمان أعني الإسلام، 5- القرآن الكريم أو منطق التحقيب، والوعي بالمطلق أو الشهود أو الاستخلاف. لذلك فمنه دون أي مصدر آخر نستمد هذا التحقيب المؤسس الأول. وله فرعان، تاريخ الرسالات الأساسية أو التدرج نهو الإنسانية الشاهدة لا الجاحدة في حركة المد والجزر على المستوى الرمزي والروحي، ثم تاريخ الحضارات الأساسية أو التدرج نحو الإنسانية الشاهدة لا الجاحدة في حركة المد والجزر على المستوى 
الواقعي التاريخي. وذلك هو المدلول الجوهري للتحقيب الذي غايته تأسيس التنظيم الجماعي الملائم لمنزلة

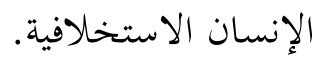

الفرع الأول: مخمس الرسالات المؤسسة التي مثلت المراحل المعدة لاكتمال المضمون الديني في التاريخ كما تعين في الإسلام، أعني رسالات أولي العزم من الرسل المتقدمين على الرسول محمد صلى الله عليه وسلم: الآدمية والنوحية والإبراهيمية والموسوية والعيسوية. أما الإسلام فهو حوهرها الذي تستمد منه قيامها ووعيها المتعالي عليها: إنه بدايتها وغايتها ونَسْغ الحياة المتصل فيها ضمانا لبقاء السليم منها وحفظا لها من السقيم. لذلك فهو ليس رسالة سادسة، وإنما هو جوهر الرسالة في كل الرسالات الأخرى المتضمنة للجزر والمد في التدرج الإنساني نحو الإدراك السليم لعلاقة الاستخلاف أو لشهود المطلق. 1- مضمون الرسالة الآدميّة: المرور من الزمان الطبيعي إلى الزمان التاريخي (الوقت) بفضل نظريّة الاجتباء، الذي هو شرط الحياة الجنسية الشرعية أو شرط تأسيس المؤسسة الأسرية في مدلولها الخلقي الروجي، وتحويل العلاقة الجنسية إلى علاقة تعاقدية تنبني عليها الحضارة الأسرية، في إطار الانتساب إلى الأمة الإسلامية (الميثاق مع أبناء آدم وهم في ظهره).

2- مضمون الرسالة النوحيّة: المرور من المكان الطبيعي إلى المكان التاريخي (الحوز). ويرمز إلى ذلك إعادة إيجاد كل الموجودات الحية بعد الطوفان، وما السفينة إلا الحضارة الإنسانية الشاهدة بعد غرق الجاحدين الرامز لكل حضارة تستعصم بغير الله. وذلك هو شرط تأسيس المؤسسة الاقتصادية في مدلولها الخلقي الروحي، وتحويل العلاقة الرزقية إلى علاقة تعاقدية تنبني عليها الحضارة المنشأية في إطار الانتساب إلى الأمة الإسلامية.

3- مضمون الرسالة الإبراهيميّة: الوعي بهذين المرورين من الزمان والمكان الطبيعيين المتقدمين عليه إلى الزمان والمكان الخنقيين الروحيين المتأخرين عنه، بفضل إدراك الأساس الواصل بينها أربعتها، شهود الخالق

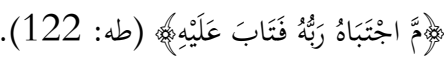
14

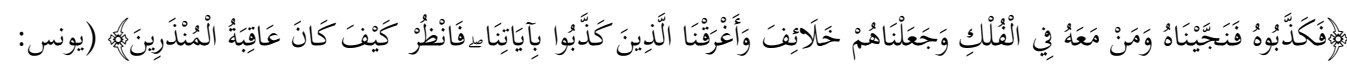


المؤِسّس لوجود المخلوق: الإِكار أو التساؤل الإبراهيمي في آيات الأفول. 16 ويقابل إنشاء المؤسسة التعليمية أو المدرسة في مدلولا الخلقي الروحي في إطار الانتساب إلى الأمة الإسلامية (التعليم باسم الله، أو آيات القرآن الكريم).

4- مضمون الرسالة الموسويّة: إصلاح التحريف الذي نتج عن نسيان الرسالة النوحية. ولذذه العلّة كان تحريف الرسالة الموسوية عودة إلى ما كانت الرسالة النوحيّة ردا عليه. إذ سعى محرَّةَة التوراة إلى استعباد كل البشر بالعجل الذهبي. فإذا ما أتى ردا على العبودية وتسخير فرعون لبني إسرائيل، أو على تناقضات المجتمع المدني وفساد الجماعة عند تحول المنشأة الاقتصادية إلى مصدر للعبودية، ينقلب هو الآخر إلى عبادة رمز هذا الاستعباد: العجل الذهبي. 18

5- مضمون الرسالة العيسويّة: إصلاح التحريف الذي نتج عن نسيان الرسالةالآدمية. لذلك انقلب

تحريف العيسوية إلى ما كانت الرسالة الآدمية ردا عليه: نظرية الخطيئية الموروثة، أو نكران الاجتباء. 19 فتحول توفيق المجتمع السياسي إلى "جيتو" عصبي دموي، وبلغ التميّز اليهودي بمفعول التحريف إلى الذروة: تأليه أحد أبناء الشعب المختار أو النعاج الضالة التي أراد عيسى تنبيهها. وفسدت الجماعة الروحية فانقلبت الأسرة العقدية مصدرا للعنصرية.

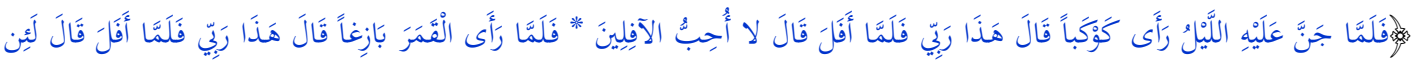

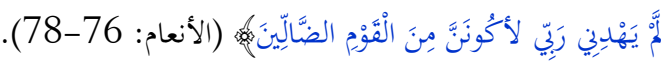

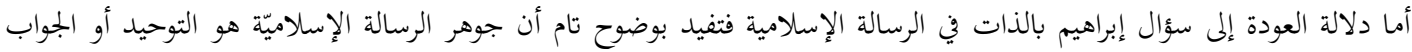
17

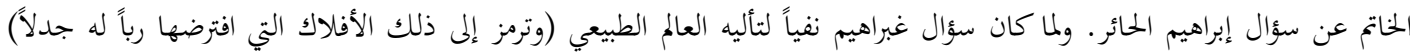

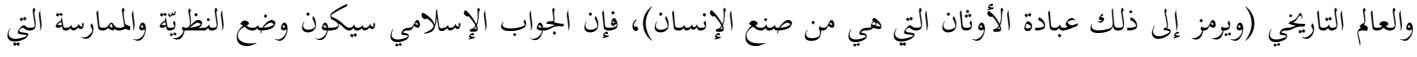

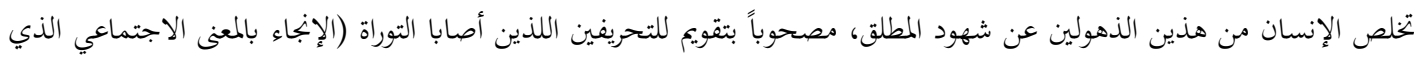

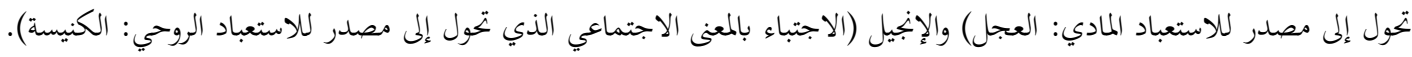

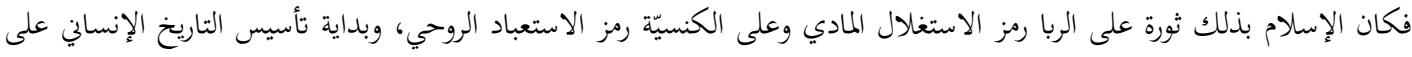

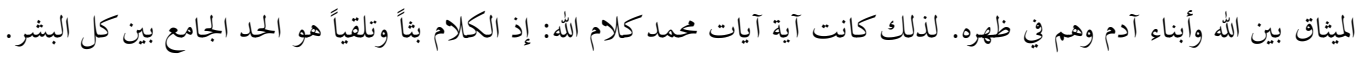

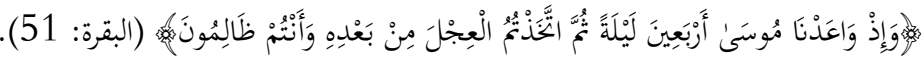
18

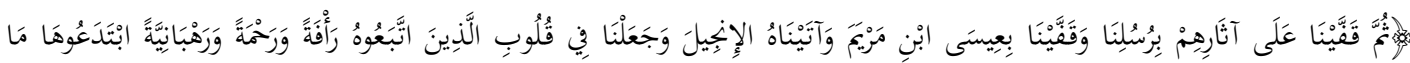

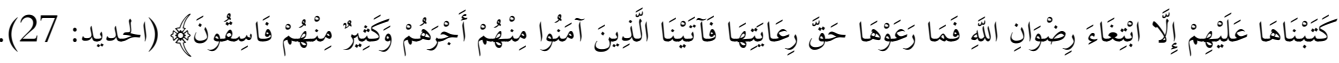


الوجه الثابت من 1+2+3+4+5 هو جوهر الديني عامة وهو مضمون الرسالة الممّمدية أو الإسلام المطلق كما تعين في الإصلاح الذي جاء به الوحي الخاتم للتحريفات تذكيرا بالحقيقة الدينيّة الثابتة كما تَعيَّن

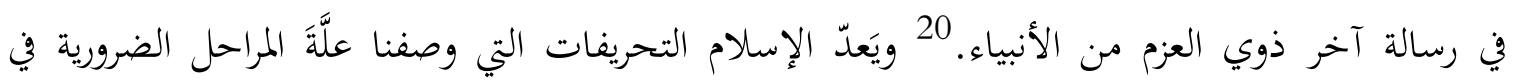
التطور الإنساني، مبرزا المضمونات الأصلية الخمسة المقصودة، أعني: البعد الآدمي أو حب الجمال المشروع في العيني لشهود الجميل المطلق فيه، والبعد النوحي أو حب المال المشروع في العيني لشهود الجميل المطلق

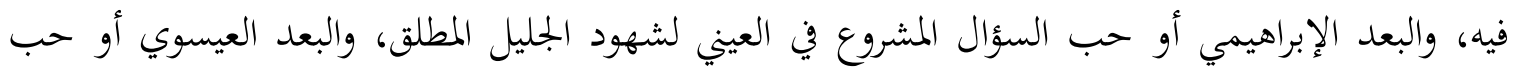
الكمال المشروع للتحرر من تأليه الجمال العيني لشهود الجليل المطلق فيه. وإدراك هذه الوحدة، وحدة الجمال والمال والسؤال والجلال والكمال المشروعة في الأعيان بما هي آيات الفعل الإلهي في العالم، هو المنطلق إلى شهود صفة الوجود بالوجدان في حال التواجد الصاحي الذي لم يبلغ إليه إلا الرسول محمد صلى الله عليه وسلم (الغزالي: مشكاة الأنوار)، لأنه هو الوحيد الذي سعى إلى تحقيق ذلك في التاريخ الفعلي: أعني تحقيق الشخص الفردي والجماعي ذي الجمال والمال والسؤال والجلال والكمال المعبر عن شهود آيات الرب في الوجود، أعني الإنسان الحر فعلا استنادا إلى الشهود ورفضا للجحود، وهو معنى تكليف الأمة الإسلامية بقيادة الإنسانية في التاريخ الفعلي وليس فقط في مجرد العقيدة الدينية. 21

20 ل الا أحد يستطيع أن يحدد مضمون الإسلام تحديداً همائياً وحصرياً. لكن ذلك لا يستثني القول بأن القرآن الكريم هو هذا المضمون الذي

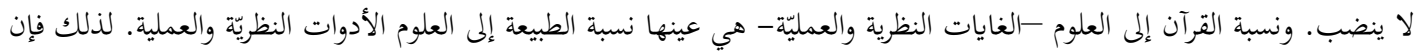

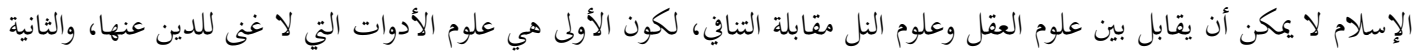

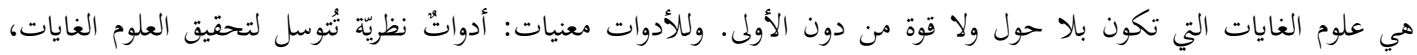

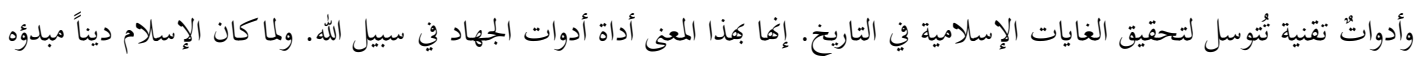

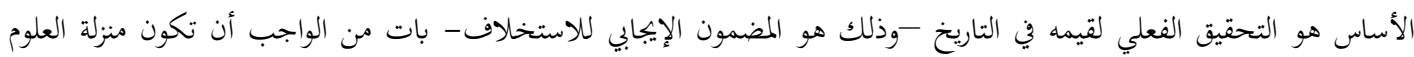

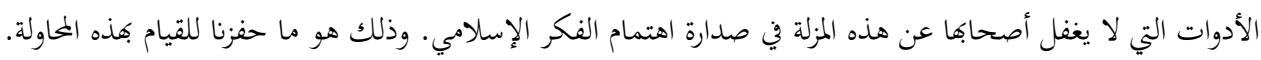

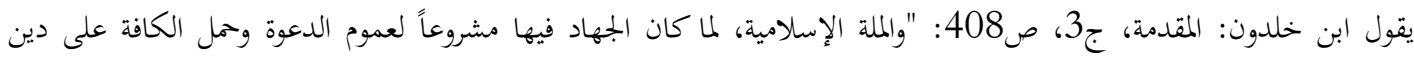

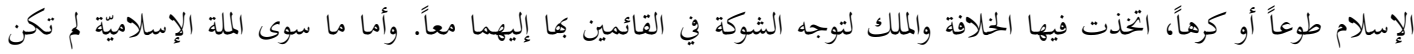

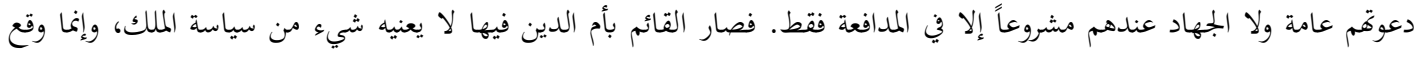

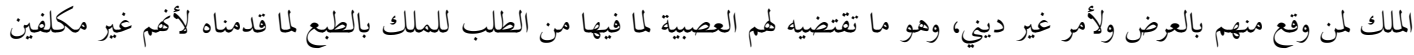

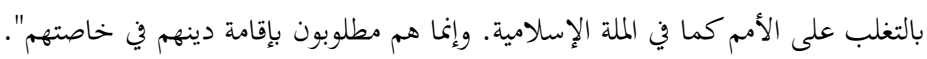


أما تحريف الرسالتين الرابعة والخامسة (الموسويّة والعيسيّة) المذكِّرتين بنسيان الرسالتين الأولى والثانية (الآدميّة والنوحيّة) فمعلومان أغما تحريف التوراة والإنجيل. ولكل من التحريفين وجهان متقابلان هما في الحقيقة الشيء نفسه. إفما العودة إلى ما أتت الرسالتان الأوليان للتنبيه إلى وجوب بتنبه: الأول: حب الجنس لذاته، ويقابله حب التأله الروحي أو الشهود لذاته (والجنس رمزه وأداته). والثاني حب المال لذاته، ويقابله التأله المادي أو حب التجبر لذاته (والمال رمزه وأداته)؛ وحب الشهود لذاته وحب التجبر لذاته مثلهما مثل مقابليهما: كفرانٌ بربٍّ العالمين مصدره عبادة الفاني الخارجي أو النفس. وبذلك يكون التحريف الثاني والأخير (أعني تحريف دين عيسى) نفيا للتذكير العيسوي بمضمون الرسالة الأولى (رسالة آدم)، أي الاجتباء والنذر مؤديا على التوحيد بين الجنس (الأول) والإثم (الأخير)، ويكون التحريف الأول (تحريف دين موسى) نفيا للتذكير الموسوي بمضمون الرسالة الثانية (رسالة نوح) أي الإنجاء، فيؤدي للتوحيد بين المال والسلطان (الثاني). فيصبح القوم الذين خلصهم موسى من العبودية ساعين بعبادة العجل إلى استعباد جميع البشر.

أما الرسالة الإبراهيمية فإها لا تحريف لها، إذهي عديمة المضمون المفصَّل، وإنما هي مجرد تساؤل يكون جوابه الرسالة المحمديّة (مثلما أن سقراط لا مضمون مفصل لتساؤله الذي سيجيب عنه أفلاطون). لذلك فإن الأفلوطينية هي في الحقيقة سقراطية محدثة ذات مضمون موجب ومفصل، مثلما أن المحمدية هي إبراهيمية محدثة ذات مضمون موجب ومفصل. ومثلما يمكن أن نعتبر السقراطية قد ارتفعت بالوجه الفلسفي من السؤال الإبراهيمي إلى قمته العقلية والروحية، فإنه يمكن أن نعتبر المحمّدية قد ارتفعت بالوجه الديني من الجواب الأفلوطيني إلى الذروة العقلية والروحية. وتلك هي العلّة العميقة للمحاولات التي اكتملت عند ابن سينا والغزالي سعيا إلى بتحاوز التقابل بين التجربتين الدينيّة الصوفية والفلسفية العلمية. ولا يمكن أن نعتبر التماثل بين النسبتين تسوية بين جديّيْما: فليس سقراط كإبراهيم ولا افلوطين كمحمد، بل التماثل هو بين النسبتين فحسب. ولم يكن بوسع اللأفلاطينية أن تكون الغاية المحيطة ليس لأن المحمدية، بخلاف الأفوطينية، تحقق الإحاطة انطلاقا من التجربة الدينية الصوفية العامة فحسب -في حين أن التجربة الفلسفية الصوفية التي تنطلق منها المحاولة الأفلوطينية لا يمكن لها أن تبغ العموم، بل تبقى مقصورة على الخصوص وهو ما لا يناسب الارتفاع بالإنسانية كلها إلى الإسلام أو المنزلة العامة التي للإنسان كإنسان -وإنما كذلك لأن 
التجربة الفلسفية العلمية الصادقة هي نفسها تجعل التجربة الدينية الصوفية ببعديها العام والخاص غايتها القصوى: فليس النظر إلا من أجل العمل في جميع الفلسفات والعلوم؛ وحتى تخليصه الواجب من النزعة الذريعية فإنه شرط في بلوغه إلى أقصى غاياته العملية السامية: إذ الحقيقة النظريّة عندئذٍٍ تصبح من جنس الحقيقة العلميّة لكوها مقصورة على معرفة الحقيقة لذاتا، أي البحث عن الصدق لوجه الله.

الفرع الثاني: مخمس الحضارات المؤسِّ: أعني حضارة الأسرة والجمال، وحضارة المنشأة والمال، وحضارة المدرسة والسؤال، وحضارة الدولة والجلال، وحضارة الأمة والاكتفال. أما البالغ إلى الوعي .جا والجامع لها جمعا فعليا دون أن يكون عنصرا سادسا فهو مقوّم الاستخلاف أو الأخوة الإنسانية ورعاية العالم الذي استخلف الله فيه الإنسان ليكون راعيا له. ففي صلة الرحم (حضارة الأسرة والرسالة الآدمية) وصلة المصلحة المعيشية (حضارة المنشأة والرسالة النوحية) وصلة المعرفة الوجودية (حضارة المدرسة والرسالة الإبراهيمية) وصلة تناقض المصالح (حضارة الدولة والرسالة الموسوية) وصلة التوفيق بين المصالح (المجتمع والرسالة العيسوية)، يكون الثابت صلة الأخوة الإنسانية المتناغمة مع كل المخلوقات، أو الاستخلاف الذي ينبني عليه الوجود الإنساني بما هو شهود للمطلق (حضارة الأمة بالمعنى الإسلامي للكلمة والرسالة المحمدية بما هي الكلي في الشأن الديني).

\section{الدليل الوجودي والقيم الاستخلافية}

تحددت آثار الروحانية الإسلامية في جوهر الفكر الفلسفي الإسلامي من خلال العمل الأساسي الذي أدته محاولتا ابن سينا والغزالي الساعيتان إلى بحاوز التقابل بين الفكرين المشائي الصفوي (الأول) والكلامي الصوفي (الثاني)، ذلك التقابل الذي هو في جوهره تقابل التجربة الفلسفية العلمية والتجربة الدينية الصوفية، أعني فصام الفكر الإنساني. والمعلوم أن الإسلام قد جعل من مهامِه الأساسية علاجَ هذا الفصام وتحرير الإنسان من نتائجه الوخيمة، وخاصة فصام المقابلة بين الروح والجسد نفسيا، والعقلي والمادي نظريا، والديني والسياسي عمليا، والواقعي والقيمي فلسفيا، والدنيوي والأخروي دينيا. لكن أكبر المسائل التي تعينت فيها ثمرات هذه المحاولة عند قطبيهها ابن سينا والغزالي هي من دون شك إشكالية التوحيد الأولى، أعني إثبات الوجود الإلهي بالدليل الذي أصبح يسمَّى فيما بعد بالدليل الوجودي. ويعد الطابع الاستخلافي ميزَّ 
هذا الدليل في الفكر الإسلامي عن صوره اللاحقة في الفلسفات الغربية الحديثة (منذ ديكارت)، تلك الفلسفات الراجعة إلى الكلام القائل بالحلول من حيث الإشكاليات الميتافيزيقية الأساسية.22 ولا معنى ملحاولة إثبات التميز عما تقدم الفكر العربي الإسلامي فيه هذا المجال، لأن الدليل الوجودي لم يصبح من مقومات تاريخ الفكر الفلسفي إلا بفضل هذين الفيلسوفين المسلمين.

لا خلاف في كون الصيغة السينويّة الغزاليّة من الدليل الوجودي الاستخلافي قد استندت إلى الفصل بين الماهية والوجود، مثل الفلسفات اللاحقة التي أخذت عنهما هذا الانقلاب النظري في تاريخ الفكر الفلسفي. لكن الفصل بين الماهية والوجود عندهما مشروطٌ بقيام الماهية المنفصلة عن الوجود (الذات الممكنة الوجود) بذات مطلقة ماهيتها هي عين وجودها (الذات الواجبة الوجود)، وإلاّ فإن الماهيات التي لا يكون الوجود مقوِما لها تكون قائمة بالعدم! لذل فإنه يمكن أن نقول إن حجة كنط ضد الدليل الوجودي الديكارتي مشروطةٌ بالقول الضمني ببعض صيغته السنيويّة الغزاليّة: الفصل بين الماهية والوجود. لكن الجزء الأهم من الصيغة السينويّة الغزاليّة هو القول بأن الماهيات الممكنة ماهياتُ معلولةٌ قائمة بغيرها المشروط بكونه ذاتا ماهيتها هي عين إنيتها. ولا معنى للأولى إلاّكوغا تفترض هذا الغير الذي تتضمن ماهيته وجودَه، تضمنا يغنيه عن القيام بالغير، وإلاّ فالقيام يكون من جنس تسلسل العرائس الروسية: وبذلك ندرك جوهر الفرق بين الدليل الوجودي الحلولي والدليل الوجود الاستخلافي كما صاغه الغزالي أفضل صياغة في مقاصد الفلاسفة عندما حدد علاقة الإنية بالماهية في نوعي الموجود الممكن والواجب.23

$$
22 \text { وهو ما تم لنا عرضه نقدياً في مقال سابق بعنوان: "الدليل الوجودي الحلولي"، مرجع سابق. }
$$

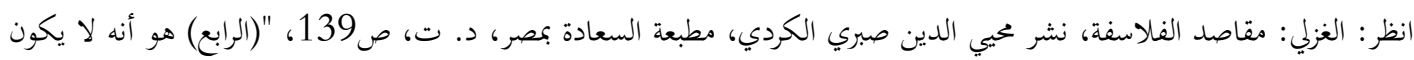

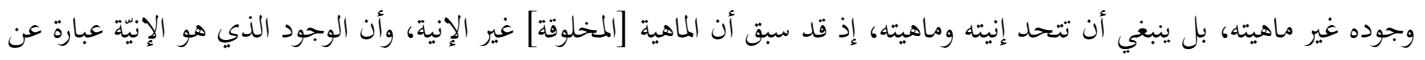

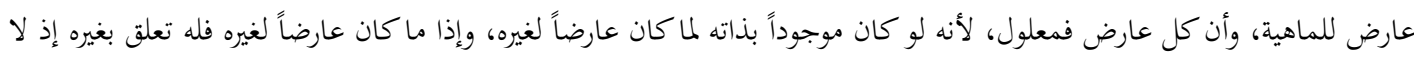

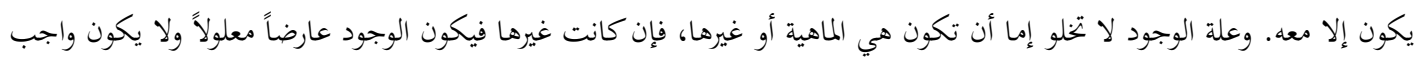

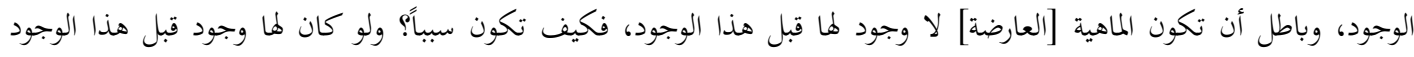

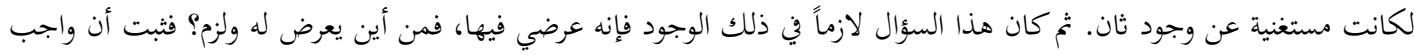

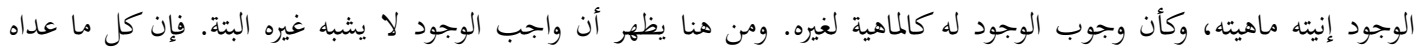

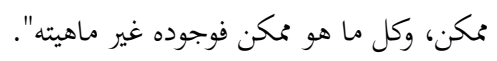


إن التشكيك في وجود العالم الحنارجي -عند ديكارت- ينبغي ألاّ يتوقف عن وجود ما هو غير الذات المفكرة. فالذات نفسها، لا مجرد حسمها، وقبل هذا الفصل الوهمي بينهما، تعي نفسها بصفتها موجودة خارج وعيها، أي أن وجود الذات ليس مجرد ظاهرة شعورية مضمونية. وحتى لو سلمنا بكون الذات ظاهرية شعورية، فإنا ليست ظاهرة شعورية مضمونية، وإنما هي الظاهرة الشعورية التي يقوم بها المضمون الشعوري، وليست هي هو. ولا فرق يذكر بين وعيي بذاتي خارج هذا الوعي ووعيي بغيري خارجه، بل إن صدقَ هذا أكثر معقولية وصوابا من صدق ذاك، لذلك فإنه لا يمكن أن نقبل استثناءَ ديكارت للواجدية الإنسانية من الحاجة إلى ضمانة الصدق الإلهي ضد الحذاع الشيطاني، لكون هذه الضمانة شرطَ وجودٍ الوجدانية الإنسانية، كوغا شرط موجوديتها وموجودية العالم الخارجي، وللتلازم بني الواجدية الإلهية والإنسانية والوجود بالذات للموجودية الإنسانية والإلهية أيضا. فاستثناء ديكارت للذات التي تقول "أفكر" من الخداع الشيطاني - هذا الاستثناء الذي تعود إليه جميع الفلسفات القائلة بالوحدانية الانطوائية وقوفا عندها كأغها فوق الشك وتدليلا على العجز في إثبات الوجود الخارجي، ظنا منهم أن التشكيك في وجود العالم الخارجي لا ينال ذات الإنسان بما هي ذاتُ مفكرة عند فرضها غيرَ كياها العضوي- لا مسوٍّ له عدا الظن بأن وعي المخدوع بكونه مخدوعا حالَ الخداع يثبت كونه ذا وجودٍ غير وجوده المخدوع في وعيه، وهو قول لا يقبل إلا بأحد

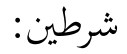
- - إما ثبوت وجود الموضوع الذي تؤثر فيه العلّة وراء وعيها بفعلها فيه، أعني أن خداع الشيطان عند مخادعته لي يؤكد وجودي بصفتي موضوع الخداع، وجودا يكون غير الشعور بكوني مخدوعا، وهو قبول ضمني بمبدأ العلية يتناف مع الشك المطلق المزعوم؛ - أو ألاّ يكون لوجودي في وعيي الذي هو بمنأى عن الشك حقيقة وراء هذا الوجود في الوعي لكوها إن وجدت فإنا لن تتخلص من الشك إلاّ بفرضية الصدق الإلهي، فيكون إدراك الذات الثابت لوجودها غير القابل للشك لا يتضمن حقيقتها، وتكون هذه الحقيقة مثل العام الخارجي غير مستغنية عن الضمانة الإلمية. 
لذلك فإن الدليل الوجودي ينبغي أن يكون متقدما على الكوجيتو لأنه صدقِه وليس إلاّ الترجمة الفلسفية لمنزلة الاستخلاف التي هي جوهره. فالوعي بالتلازم بين الوجود الممكن بما هو بجرد حاصل -بما في ذلك وجودي- والوجود الممكن بما هو واجب الحصول، إن الوعيَ بهذا التلازم هو الضمانة الوحيدة لقيام الذات ولصدق وعيها بهذا القيام، ولا حاجة لحصر منطلق هذا الاستدلال في الوجود الذاتي، بل المقصود هو الانطلاق من الوجود الممكن الحاصل أيا كان، إذ كان الكوجيتو بحاجة إلى الضمانة، وإلاّ فإن ديكارت يكون قد بيّن أنه موجودٌ في وعيه المخدوع فقط لا موجود بحق. والوعي بهذا الإمكان المستند إلى الوجود الواجب هو الاستخلاف الذي لا يختص الإنسان إلاّ بالوعي به لا غيرن وتشاركه جميع الكائنات الأخرى فيها بقيامها الإمكاني، وذلك في كلتا الحالتين، الصدق والحداع: فإذا كان هذا الوعي صادقا كان ذلك كافيا، وإذا كان خادعا كان الخداع، على الرغم من كونه خداعا، ذاكثافة وجودية كافية لإيجاد الشعور بعدم الخداع، إذ الشعور الخادع بالخداع سلب سلبٍ وهو إذا إيجاب! فإذا كان الشيطان يخدعني بأنه يخدعني فهو لا يكذبني بل يصدقن. وذلك كافٍ للحصول على صدق أول يخلصني من خداع يجعلني أظنّ أن وعيي المتضمِّن لوجهي الإدراك -الحصول المجرد والحصول الواجب- خادعٌ ويْبقيني في الانطوائية. والانطوائية هي الخداع الشيطاني إذ به أؤلّه نفسي فأؤِّس عليها أن إدراكي كافٍ وحده ليقوم به مضمونه، دون أن يكون هو ذا قيامٍ موضوعي، ودون أن يكون هذا القيام الموضوعي الذي هو مجرد حصول مستنِدا إلى القيام الواجب.

فلو بقيت عند إثبات وجودي في وعيي ضد الخداع الشيطاني لَتَعَنَّرَ عليَّ الانتقال إلى وجود حقيقي يكون لي وراءَ هذا الوجود في الوعي المخدوع دون القبول بأن بعضَ الماهيات (=الوجود التصوري في الوعي) لا يقتصر قيامها على الوجود التصوري، بل لها بذاتها القيام الوجودي غير المقصور على التصور. فيكون ديكارت قد اعتمد ضمنيا على الدليل الوجودي في إثبات الكوجيتو، على الرغم من عدم شعوره بالحاجة إليه إلاّ عند اضطراره إلى إثبات حقيقة العالم الخارجي: فما الدليل الوجودي إلاّكون الماهياتِ التي لا تقتضي ذاتحا وجودَها ملازمة لما له من ذاته الوجود بصفته مقوّما وليس مهمّا إذا كانت هذه الماهية هي ماهيتي أو أي ماهية أخرى. وإذا صح هذا على الناقص من الماهيات، فمن الأولى أن يصح على التام منها، علما بأن 
الإنسان السليمَ المدارك لا يَنْسِب نفسه التمامَ والوجوبَ الوجوديْين، بعد أن تبين أغما لا مفرَّ مهما حتى للكوجيتو إذا فرضناه مستغنيا عن الدليل الوجودي.

والمعلوم أن إدراكَ الذات لذاتما يتضمن إدراكَها لحقيقتها وراء وجودها بصفتها حقيقة خارجية، أو مضمونا معرفيا يتجاوز الوجود الجمرد في الوعي حتى بما هو وعيُ، لكونه وعيا بوجود الذات الناقصة المصحوب بالوعي بالاستناد الضروري إلى الذات التامة؛ وذلك هو الثهود الذي هو عيْن الوجود الذاتي الحقيقي غير المقصور على وعي الذات بذاتها، إذا اعتبر مجردا وبانفصال عن هذا لشرط المصاحب له. فما ينتهي إليه تعجيز اشيطان المخادع ليس هو إثبات وجود الذات في وعيها بجردا، بل هو إثبات صدق الوعي بوجود الذات الحقيقي امتحانا يوصل إلى وجوٍٍ مطلق ضامن ضد العدم، أعني أن الشيطان المخادع عاجزٌ عن محوِ الميثاق أو الفصل بين الوجود الإنساني والوجود الإلهي.24 فما هو ثابتُ وبمنأى عن اشك ليس هو وجودي وجودا ذهنيا في وعيي، وإنما هو صدق هذا الوعي، هذا الصدق الذي يعني أن وجودي حقيقي، وجودا واثقا من كونه ليس بجرد أثثرٍ ذهني في ذهنٍ هو الآخر أثر ذهني لا إلى غاية. إنه وجودٌ ثابت أمام خداع الشيطان أو العدم المصاحب لوجودي الذي يظل ممكنا على الرغم من حصوله، وتلك هي علة الحاجة إلى هذا الثبات الدال عليه استنادا إلى ضمانِِ وجودٍ يكون في غنى عن ذلك كله: الوجود الواجب.

ولو عَّض ديكارت ذلك لاستغنى عن اللجوء على نظرية العلة لإثبات الفكرة التامة، وإلى الدليل الوجودي في صيغته المقلوبة (نتيجة لا شرطا للكوجيتو) التي أعطاها له لإثبات الوجود الإلهي الضامن بصدقه وجودَ العالم الخارجي، ولاستغنى عن الدَّور الذي وقع فه في كلتا الحالتين فأصبح عنده الدليل الوجودي بمقتض ذلك أوهَى من بيت العنكبوت. فالوعي بالذات بمجرَِّهِه هو الاستخلاف، وهو عين الدليل الوجودي في معناه الأصلي: الماهية التي يكون الوجود من مقوّماتما وليس مجرد عارضٍ لها بصفتها شرطا في الماهية القابلة للفصل عن الوجود الذي يعرض لها، سواء كان ذلك في مستوى الفصل المنطقي بين الماهية والوجود

24

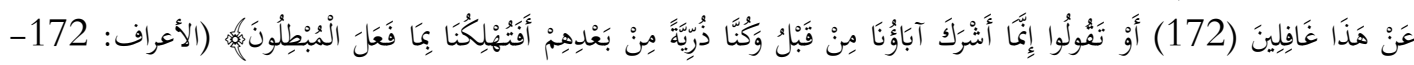


كما اقتصر على ذلك أرسطو، 25 أو في مستوى الفصل الوجودي كما أتم ذلك ابن سينا. 26 فهو عين الميثاق وعين شهودٍ النسبة بين المطلق والإضافي، المألوه والإله، النافي بالذات للحلول والرافض لقلب العلاقة التي تجعل النسبيَّ أساسا للمطلق: نظرية الإنسان المعتَبَر أساس الوجود سواء تعلق هذا التأسيس بالظاهرات أو بالباطنات بحسب الدرجات التي يزعمها بعضهم للانطوائية الإنسانية، أولئك القائلون بالمركزية الإنسانية في الفلسفة الذاتية المعاصرة. وما تلك إلاعقيدة الحلول متنكرة: العقيدة التي ليس لها مآل إلاّ الإنسية الهمجية الناتحة عن الانخطاط؛ العقيدة التي تقصر الوجودَ الإنساني على بعده الدنيوي فعلا والأخروي وهما، فتستثني كلَّ تعالٍ حقيقي لكونا تؤلّه الإنسانَ فتقضي على الإله والمألوه. ولن تكفي عقيدة يعقوبي (jacobi) المستندة إلى نظرية هيوم (hume) في العقد للصمود أمام هذه العنجهية بل هي تغذيّيها! 27 لذلك فإن الإنسان يعلم أنه ليس له، بما هو خليفةٌ، إلاّ الحكم الإنشائي والحكم الشرطي البعديان علما وعملا حقيقيين، وله كذلك القدرة على تمييز الحقيقي من الخيالي لكونه له كذلك القدرة على العلم والعمل الخياليين في فنونه جميعا، وخاصة في آدابه بصفتها البعد الخيالي من تاريخه الحقيقي في كلتا بحربتيه: الفلسفية العلمية والدينية الصوفية. والأولان، عند الاقتصار عليهما، يهِّلّان موضوعَهما إلى وهم من صنع التجربة الفلسفية العلمية البتراء: الوحدانية الانطوائية. والثانيان، عند الاقتصار عليهما، يهوِلان موضوعهما إلى وهم من اختلاق التجربة الدينية الصوفية العرجاء: العقيدة الحلولية. لذلك كان الجمع بين التجربتين والفصل بين الخيالي والحقيقي في العلم الإنساني أمرا لا يشك فهي إلاّ من يهِّل التفلسفَ إلى مهزلةٍ يمضغ أصحابها بعض الأحاجي الشكّاكية التي ترتد إلى طلب المستحيل منطقيا (تعجيز العقل بالعقل) والتي ينفيها أساسها ذاته، إذ إن المقابلة بين الخيالي والحقيقي تكون ممتنعة عندما نرد كل شيء إلى أحدهما: فهما متضايفان، ولا يمكن تصور أحدهما دون الآخر ودون الفصل بينهما.

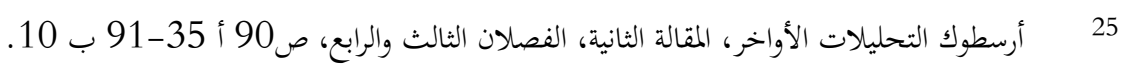

$$
\begin{aligned}
& 26 \text { 26 } 26
\end{aligned}
$$

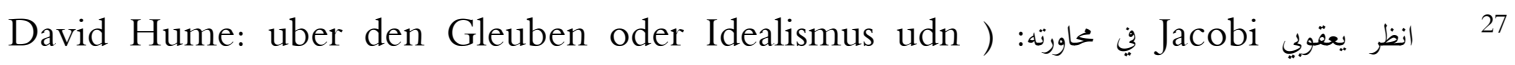
(Realismus, Ein Gesprach, von F. H. Jacobi, Ulm 1795. 
إن ما يتجاوز علمَ الإنسان يعلم الإنسان علةً التجاوز منه، فليس هو باطنا بجهولا إذ يعلم منه الوجود فضلا عن كل الصفات الأخرى التي ذكرنا، ويعلم خاصة المقصودَ بالنسبة إليه وإن جهل ذاتَه فيما يتعلق بما لا يتوجه منها إليه؛ إنه ظاهرٌ غير المعلومٍ منه هو كونه هو لا نسبته إلى الإنسان وكونه لا يقبل التعليل الذي يقصره عليه، أعني المعطى الطبيعي والشريعي وإمكان الإعطاء والتلقي وكيفهما، أو طبيعة الإدراك الإنساني المستند إلى الإيمان بالتراسل مع العلم الإلهي. وما يجهله الإنسان ويطلق عليه اسم الشيء في ذاته هو الاعتراف بفارق مطلق بين عقله والعقل الإلهي، إذ بدون هذا الشرط ما أدراه أن علمه لا يستنفد الشيءَ في ذاته؟ أليس نفي هذه المسافة هو الذي اكتمل في انطوائية/وحدانية الوجود؟ إن التشاهد بين الآله والمألوه، أو الاستخلاف، هو هذه العلاقة بين العلمين الإنساني والإلهي، وبنيته هي المسافة الواصلة، فلها حدَّان ووصلان بينهما في الاتحاهين ثم المحيط بالكل. وهذا هو أساس الميثاق أو معرفة الله الملازمة للوعي بما هو وعي: 1- الوجود الواجب أو الذات الإلهية، ثم 2- هو بصفته ما يتوجه الإنسان إليه، ثم 3- الإنسان بصفته ما يتوجه هو إلهي، ثم التوجهات أو التراسل والتشاهد، ثم 4- منه إلى الإنسان، و5- من الإنسان

فالعلم والعمل بما هما شهود المطلق إبداعُ يستكمل به الإنسان ذاته، ولا يبدع بيهما الطبيعة أو الشريعة. وإذا فمعلوماته وأعماله، حتى لو حصرناها في مجرد نسبتها إليه، فإنه ليس ربها لأها بنت ما فيه من قدرة على إبداعها وليس هو ربها. وهذه القدرة على الإبداع ليست ظاهرا من الوجود إلا إذا كان الظاهر

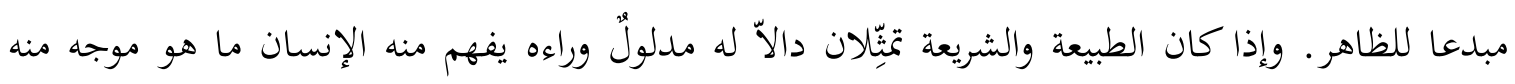
إليه، فإن الإبداعً العلمي والعملي يبدع الدالَّ الذي يعبّرّ به الإنسان عن شهوده، لا الموضوعات الطبيعية والشريعية التي يعبِّر عن شهوده إيهاها، إلاّّ إذا أطلقناه فجعلناه هو الوجود الواجب. لكننا عندئذٍٍ لا نكون نفينًا الوجود الإلهي وإنّما نزَّلنا الإنسان منزلته تخلصا وهميا منه: وذلك هو جوهر منزلة الإنسان الحلولية التي نرفضها للاستعاضة منها بالمنزلة الاستخلافية، المنزلة الوجودية التي هي المشاكلة المتصلة لشهود الآيات الإلهية لا غير. فما وجود الإنسان إلاّ شهوده الناطق نطقا متِِنّا في الرموز لآيات المشهود المطلق، وتلك هي الخلافة 
ليس العقل الإنساني إلاّ إنشاء أعيان الرموز الدالة حاسّيا، وإنشاءَ أعيان الرموز المدلولة حادِسيا (والدالّية والمدلوليّة كلتاهما نسق الإضافات بين تلك الأعيان، ونسقها ذلك هو الدال والمدلول في الوقت نفسه، إفما دالّ ما هو مشهود لنا من آيات المطلق في لتجربتين ومدلوله: والمشهود هو المرجع الذي لا يمكن أن يستفَه المدلول مهما اقترب منه، ولا يمكن كذلك أن نحدد مدى هذا الاقتراب ولا طبيعتَه لكونه نسبة المتناهي إلى اللامتناهي)، الدَّالة على آياتِ مشهودة تدل هي الأخرى على إنشاء موجدٍ لتلك الآيات، إنشائها الذي ننسبه إلى العقل الإلهي إنشاء يتحدد في الدال والمدلول الوجودَيْين (لا اللّغويين) بأعياهما التي ندرك منها ما يناسب نسبة أبعاد الواجديّة/ الشاهديّة، والموجوديّة/ المشهوديّة منا إلى أبعاد الواجديّة/ الشاهديّة والموجوديّة/ المشهوديّة الإلميتين. وذلك هو الحوار بين الذاتين المألوهة والآلهة، الحوار الذي يبدع النظر والعمل بما هما عبادتان/شهادتان: وكلتاهما تحافظان على المسافة (تحنبا لإفراط الحلول) الواصلة (بتنبا لتفريط الانفصال). العقل الإنساني لا يحاكي الموجودات بما هي حصيلة فعل الإيجاد، إنما وعيه بوجوده عينه هو شهادته آياتِ الله آمرا وخالقا، وما علم الإنسان وعمله إلاّ السعي إلى مشاكلة القضاء والقدر الإلهيين، قضاء وقدرا لما يشاء الله للإنسان أن يحيط به من علمها وعملها. فالإنسان ينشئ أعيان الدوال حابِّيا وأعيان المدلولات حادسيا عبادة يسعى بها إلى التشاكل مع الإنشاء الإلهي لأعيان الماهيات ماديا وأعيان الإنيات روحيا، دون حاجة إلى نظرية التطابق الواقعية. فالمعيار هو اتحاد القصد الشهودي بين الموجودات، لا تطابق الهيآت المعرفية مع هيآت تلك الموجودات. وعلم الإنسان وشهوده ليس تطابقا مع الموجود، بل هو إيجاد الآيات الدالة على انشداده بالقصد الشهودي إلى المشهود الأسمى: إنه الإبداع.

فما نعلمه عن الأعيان الدالة والأعيان المدلولة والذوات والوجودات، هو كوها آياتٍ دالة على القضاء والقدر الإلهين إيجادا وإرسالا، والإنسانيين علما وتلقيا، لا إطلاق ولا نسبية: عملنا وعلمنا هما مقدار ارتفاعنا في سلم الوجود بالاستناد إلى مدى تحقيقنا للشهود، شهود المطلق في آيتيه الطبيعيتين (العلم النظري أو التجربة الفلسفية العلميّة غير المستثنية للتجربة الدينية الصوفية وموضوعها) وآيتيه الشريعيتين (العلم العملي أو التجربة الدينية الصوفية غير المستثنية للتجربة الفلسفية العلمية وموضوعها) وذلك هو الاستخلاف: الحضارة الإنسانيّة في تعينها الرمزي المادي، علما بأن المادي ليس إلاّ رمزيا، ولا يختلف عن الأول إلاّ بكثافة العين الدالة من الرمز، فكل مصنوعات الإنسان رموز. ويتبين طابعها هذا عند البحث الأثري في الحضارات 
المنقرضة، فنحن نتلقاها بهذه الصفة، إذ لولا ذلك لتعذر الفصل بينها وبين أي مادة أخرى، ولاستحال فهمها، ولما توارثت الحضارات بعضها بعض. ولذذه العلة كان الخلق الإنساني لا يتعدى الخلق الفني أو الصياغة الشكلية للوجود محاكاة لما ينفعل به من إدرالٍٍ للقضاء والقدر. فالإنسان فنانُ تشكيلي يعكس ما يدركه من الإبداع الإلهي التشريعي والتطبيعي، حتى وإن أدى الوهم ببعضهم إلى تأليه الإنسان الذاتي. والفنّ الناتج عن إدراك القضاء يعطينا الفنون العملية الممكنة من الإبداع الرمزي الصانع للمؤسسات والأدوات المنظمة للعلاقة بين البشر بعضهم ببعض (خاصة السياسات والتاريخ المجردين [العلم العملي والآداب] والمطبقين [السياسة والتاريخ بالمعنى التقليدي]). والفن الناتج عن إدراك القدر يعطينا الفنونَ النظرية الممكنة من الإبداع الرمزي الصانع للمؤسسات والأدوات المنظمة لعلاقة البشر بالطبيعة (وخاصة المنطق والرياضيات المجردين [العلم النظري والأنساق النظرية الجمردة] والمطبقين [علوم الطبيعة والتقنيات]). والفن المطلق قبل هذين الفنين المزدوجين النابتين هو فن إبداع التعبير الشهودي غير الموظف لا عمليا ولا نظريا، أعني الإبداع الجمالي الخالص في فنون الأمم وآدابها بما هي ذروة التعبير عن الوعي الشهودي بالاستخلاف، أعني التعبير عن التجربة الدينية الصوفية الخالصة.

ذلك هو الاستخلاف الذي يرفض إفراطَ الحلول الإنجيلي وتفريطً الانفصال التواراتي في تحديد منزلة الإنسان الوجودية. وإلى هذه المنزلة الاستخلافية تستند أفعال العقل الإنساني وقيمها الخمس التي نصفها لاحقا. فالحكمان الإنشائي والشرطي البعديان عن الإنسان، علما وعملا، يستندان إلى التسليم بالفعلين الإنشائي والشرطي القبليين عند الله، وما المعرفة الإنسانيّة إلاّ نزوعٌ لا يقهر للوصول إلى الإحاطة بشيء من السابق في علم الله: العلم السابق الذي ننسب إليه الأمر والحلق والذي يمثل غاية بحثنا عن القوانين النظرية ومسلمته الأساسية في جميع العلوم الإنسانية. والحكمان الإنشائي والشرطي القبليان عند الإنسان علما وعملا يستندان إلى التسليم بالفلين الإنشائي والشرطي البعديين عند الله، وما العمل الإنساني إلاّ شوقُّ للوصول إلى إرضاء الله: العلم اللاحق الذي ننسب إليه الوعد والوعيد الذي يمثل بحثنا عن القوانين العملية ومسلمته الأساسية. فدون إيمان بالعلم السابق لا إمكان للعلم والعمل البعديين وجوديا والقبليين معرفيا عند الإنسان. فدون إيمان بالعلم السابق لا إمكان للعلم اللاحق لا إمكان للعلم والعمل القبليين معرفيا والبعديين قيميا عنده، أعني شرطي العمل الخلقي بالقصد الأول والعلم النظري الذي يكون في خدمته بالقصد الثاني. 
وعندئذ يمكن أن نؤسس القيم من المنظار الاستخلافي على طبيعة هذه العلاقة غير الحلولية بين المنزلة الإنسانية والمنزلة الإلهية، هذه العلاقة التي هي عينها الدليل الوجودي والقدر على التوجيه التي لعقل الإنسان المستخلَف. ذلك أن ما حاوله فلاسفة المثالية الألمانية من تأويل لرموز الوجود الطبيعي والتاريخي والتعبير عن إدراكهما كما ورد في النص الديني هو الآلية العامة التي تشترك فيها جميع مراحل الفكر الفلسفي، تل المراحل التي لا تختلف إلاّ بمضمون هذه الآلية. وسنتمكن بفضل هذا التأسيس من تحديد طبيعة القيم وحصر أصنافها وجنسها وفروقها النوعية التي ظلت حتى الآن مجهولةً الطبيعة بحكم التفريط والإفراط اللذين لم نعالج منهما إلاّ شكلهما الأخير في الأفلاطونية المحدثة الجرمانية بالمقارنة مع المراحل التاريخية التي مرّ بها، وخاصة المراحل التي حاول بعضهم إغفاها، اقتصارا على التأويل التثليثي وتأليها للإنسان.

فقد اعتاد الفكر الفلسفي والديني التمبيزَ بين أنواع ثلاثة من القيم والاقتصار عليها، دون تحديد الجنسي الجامع بينها، ودون تعليلِ عددها أو تعيين طبيعة الفرق النوعي بينها: إنها القيم الثلاث المعهودة: الحقق والحير والجمال (ومقابلاتا)، والأولى للمعرفة، والثانية للعمل، والثالثة للفنون الجميلة. لكن هذه القيم الثلاث مشروطةٌ جميعا بما يجعل أفعل العقل (النظر والعمل والإبداع)، 28 التي تعد هذه القيم وصفا لها، أمرا ممكنا، أعني "الفعل/القيمة" الشارط لها جميعا: فلو لم يكن الإنسان قادرا على إدراك الإمكان، لاستحال عليه أن يرتفع فوق الموجود ليدرك الفرق بين الحاصل والواجب. لو كان الوجود عنده منقسما إلى جهتين وحيدتين هما الضروري والممتنع لزالت المقابلة بين الوجود الحاصل غير الواجب والوجود الواجب غير الحاصل، ولما بقي غير الواجب والممتنع. إن قدرة الإنسان على التوجيه، فصلا بين جهات يضفيها على وجود الموجودات، تمثل هي الأخرى نوعا آخر من التقويم ظل مهجورا عن الفلاسفة، مما حال بينهم وبين فهم طبيعة العلاقة بين الوجودي والقيمي مقدِّمين الأولَ على الثاني، وكذلك عند رجال الدين الذين انتهوا إلى النتيجة نفسها وإن بتقديم الثاني على الأول. والقدرة على التمبيز بين الجهات أو التوجيه هو الفعل العقلي الذي يصفه الضرب الرابع من القيم. وبيّنُ أن الشرط المخرِّر من ثنائية الواجب والممتنع الفاسدين هو ما يمكِّن الإنسان من التعالي نحو الوجود والعدم الممكنين (الحرية) اللذين يردان إلى الوجود الواقع والعدم الممتنع فينقلبان إلى واجب ومتنع (الضرورة). ويحول هذا الرد دون إدراك الواجب الحقيقي (الله) ودون التمييز بين

$$
28 \text { أرسطو : أفعال العقل، المواضيع الجدلية، } 145 \text { أ 12-17، وكذلك ما بعد الطبيعة، الماء } 1025 \text { ب } 25 .
$$


المقبول والمرفوض في الحياة الإنسانية، أعني دون جوهرها التقويمي: وذلك هو فعل التجرد المؤسس للاستقلال أو التحرر من الاضطرار، أو الفعل الذي تصفه القيمة الرابعة، قيمة الحرية الإنسانية أو عبادة اللامتناهي المقابلة لعبودية المتناهي.

لكن هذا التعالي على الوجود الحاصل والتحرر منه اشرئبابا إلى الوجود الممكن، والقدرة على التمييز بين المقبول منه والمرفوض كيف يكون ممكنا؟ أي يقوم الإنسان وكيف عندما يتعالى فيطفو فوق المجرى الواقع للوجود الطبيعي والتاريخي الخارجي ونظيرهما الداخلي ليتمكن من السيادة عليهما؟ كيف يكون الوجود الحاصل محوطا من كل الجوانب بالوجود الممكن، مثل القشة تحيط بها أمواج المحيط تتقاذفها، دون أن يكون بينه وبين وجودٍٍ أتمّ منه بونُ يدركه الإنسان، وتكون النسبة بينه وبين هذا الوجود الأتم كالنسبة بين التام والناقص، وبين اللامتناهي والمتناهي؟: فعل الشهود أو وجدان المطلق الذي يترجم فلسفيا بالدليل الوجودي ودينيا بمفهوم الميثاق أو بمنزلة الاستخلاف، إنه الفعل العقلي الذي يصفه الضرب الخامس من القيم.

فإدراك البون بين الحاصل والممكن أو التوجيه (الضرب الرابع من القيم) يدل على هذا الشهود (الضرب الخامس من القيم) وينتج عنه. وهو يقلب ترتيب الشرف، فيجعل الممكن الوجودي المعبر عن المسافة بين الممكن والواجب (الدال على حرية الإرادة الإلهية المطلقة) أسمى قيمة من الحاصل الوجودي (الدال على المفعول النسبي الذي لا يستثني غيره)، على الرغم من كون الحاصل، من المنظار الفلسفي القديم، يعٌَّ عادة أكثر كثافة وجودية من الممكن، لكونه بالفعل ولكون الأول مجردَ قوةٍ، حسب ظن من يتناسى الفصل بين الإمكان بما هو إدراك للفرق بين الحصول المجرد والوجوب أو الإمكان بمعنى عدم التحقق. ذلك أن السمو الدال على إدراك الواجب هو الذي يمكّن الإنسانَ من الإفلات من سلسلة الوقوع الضروري ليتعالى عليها، فينتقل إلى نظام الغاية الحر. وذلك هو ما يرمز إليه قَلْب قانون الطبيعة وإخضاعه إلى القانون الخلقي: قانون الأمر الواجب (الحاصل فعلا في الشرائع الإلهية لا المقصور على الافتراض والتسليم كما هو الشأن عند كنط) في رمز عصيان إبليس، بحجة رفض ما يؤدي إليه الأمر بالسجود من قلب للقانون الطبيعي: قانون الأمر الواقع. فسجود ذي المعدن الناري لذي المعدن الترابي يناقض الحركة الطبيعية التي لمما كليهما في الفيزياء القديمة. 
وبذلك نفهم أن إجماع المتصوفة على رفض القانون الخلقي الذي تعدّه مجردَ رسم لم يكصل بمعزل عن قولها بعقيدة الحلول والانطوائية، وهي تشوه الفكر الديني الصوفي غير المتنافي مع الفكر الفلسفي العلمي كما يحددها الموقف الاستخلافي، إذ هي تكتفي بالعودة إلى القانون الطبيعي" تقديما لوجودي مبتور على قيميّ مجزوء، ورفضا للقانون الخنقي أو اتباعا للفتوة الإبليسية المزعومة. 29

فهذا الإدراك هو شهود المطلق أو الإيمان بالله المحرِّر من كل معبود سواه، أي المحرر من كل ما يشد الإنسان إلى الحاصل من الوجود فيمنعه من التعالي عليه إلى مملكة الغايات المحددة للبون الفاصل بين الحاصل والواجب. وتلك هي القيمة الخامسة، أعني الشهادة، أو العبادة، أو الأمانة، أو العقل في معناه الديني العميق، أي جوهر الوجود الإنساني أو الميثاق. وبذلك تكون أفعال العقل والقيم التي تصفها هي الآتية: فعل الشهادة أو إدراك المطلق إيجابا أو سلبا وقيمتاه الشهود والجحود؛؛ ثم فعل التوجيه أو إدراك الجهات وقيمتها الحرية والضرورة؛ ثم فعل الإبداع المعبر عن إدراك المطلق والحرية، وقيمتاه الجميل والذميم؛ ثم فعل العلم المحقق لهما في التاريخ، وقيمتاه الحسن والقبح أو الحير والشر؛ ثم فعل العلم بكل ذلك، وقيمتاه الصدق والكذب. وليس فعل الشهادة أو الوعي بالمطلق إيهابا وسلبا (الشهود والجحود) إلاّ جنسَ أنواع الأفعال التي تصفها القيم: جنسيها الجامع المانع، ومن ثمَّ فهو أساس جنس القيم الذي هو في الوقت نفسه "فعل-قيمة-وقيمةفعل"، أعني إدراك المطلق أو الدليل الوجودي. وانطلاقا منه يمكن تحديد طبيعة الفرق النوعي بين القيم وعلة كوها خمسا لا ثلاثا:

1- فالجمال ينبغي فهمه على النحو الآتي: إن الجمال، بصفته نعتا يضفيه هذا الشهود على المشهودات إذا أدرك فيها آيات المشهود المطلق، ليس هو قيمة إلاّ من حيث هو تعبيرٌ عن الحب؛ إنه ثمرة كيفيّة الإدراك وليس صفة ذاتية للمدركات. لذلك فإن القيمة الجمالية هي، في الحقيقة، قيمة الحب في بعدها الذوقي، أو هي الجاذبية الحيوية التي أسمى تعيناتِا الشوق الجنسي النابع من كيفية إدراك صفة الحياة في الأحياء، صفة الحي المطلق عندما تشع على الموجودات الشخصية في تعينها الدال على تلك الصلة بالمطلب.

$$
292
$$


2- والحير هو حب أدوات القدرة أو الملكية؛ أي أنه ثمرة كيفية إدراك صفة القدرة التي للمطلق في العيني عمليا، ولا اعتبار للخلط الفلسفي بين القيم. فالمعنى الأول للخير هو الرزق والملكية (يملك لنفسه أدوات القدرة ورموزها الماديين). والأخيار الأخرى مشتقة منه إن لم يكن مدلولها مجازيا أو لم تكن ناتحة عن موقف تحقيري مُّاّ يوسم بالقيم المادية التي تعد من أهم أبعاد الحياة الإنسانية من المنظار الديني، إذهي جوهر وراثة الأرض. والرزق دينيا هو إما مقدار الوجود الذي للموجود، أو مقدار رمزه الدنيوي، أو المال، أو متاع حياة الدنيا سببه الأساسي: النائب الرمزي.

3- والصدق هو حب الإدراك والمعرفة؛ أي أنه ثمرة كيفية إدراك المطلق في العيني معرفيا: كيفية إدراك صفة العلم في المعلومات، أعني بعدها الشاهد الرامز لبعدها الغائب، إذ ليست المعلومات إلاّ مثالا من النظام العقلي الذي يبقى دائما غاية لا تدرك وراءها بصفتها أحد تعيناته.

4- والحرّية هي حب العزة أو السلطان بكل معاني الكلمة (القوة)؛ أي أهما ثمرة كيفية إدراك آيات المطلق في العيني سياسيا (حب التأله عند ابن خلدون): كيفية إدراك صفة الإرادة في المرادات. وإلى القيمة الثالثة أداة والقيميتين الأوليين غايتين نسبيتين يستند الحقّ المشاع في الحرية، أعني في التشريع للوجود الإنساني الجماعي.

5- وإذا فالقيم الجزئية الأربع ليست إلاّ فروعَ القيمة الخامسة وتعيناقا، هذه القيمة الخامسة التي هي الوعي بالمطلق والشوق الوجودي إليه، أعني جوهر الوجود الإنساني أو شهادة الشهود: كيفية إدراك صفة الوجود في الموجودات أو شهود آيات المطلق بوصف الموجود الممكن الحاصل متضمنا في ذاته ضرورةً الدلالة على الوجود الواجب. وذلك هو مضمون الدليل الوجودي.

وإذا فالقيمة الأصلية، هي القيمة الخامسة: شهود آيات المطلق أو جحودها، أعني جوهر الوعي بمجرده الذي هو الميثاق دينيا والدليل الوجودي فلسفيا، ثم تليها الأولى إلى الرابعة تباعا. والأولى أقرب إلى الخامسة، إذا أغلقنا المخمس. والمعرفة أو القيمة الوسطية بين المتقدمين عليها والمتأخرين هي الحدّ الفصل بين آيات السيادة الإنسانية الطبيعية له دون جهد واع منه (الخلق) وآياتما الواعية الناتجة عن المجهود المقصود والكسب (الأمر). إها إذا في الوقت نفسه دليل النقلة من الوجود الطبيعي البسيط إلى الوجدان الشريعي 
المركب وسبيله الوحيدة الممكنة للإنسان. لذلك فهي الأمر المشترك البسيط إلى الوجدان الشرعي المركب وسبيله الوحيدة الممكنة للإنسان. لذلك فهي الأمر المشترك بين التجربتين الفلسفية العلمية والدينية الصوفية. فإذا التفتت إلى المتقدمتين عليها دون الانطلاق من المتأخرتين أو إلى المتأخرتين دون الانطلاق من المتقدمتين كانت تجربة مبتورة تفسد الوجود الإنساني وتحول دون الشهود في عبارتيه: الفلسفية أو الدليل الوجودي، والدينية أو الميثاق.

ذلك أن هذه القيم ترتبط ارتباطا حميميا بنظريتيْ الصِّفات الإلهية والمدارك الإنسانية التي تتعلق بها: فالحب الذوقي متصل بصفة الحياة الإلمية وبحاسة الذوق الإنسانية في بعدها الروحي أو الذّويقة، وبمفعولها المادي أو الذوق الحسي. والحب المالي متصل بصفة القدرة الإلمية وبحاسة اللمس الإنسانية في بعدها الروحي أو اللّميسة، وبمفعولما المادي أو اللمسنَ الحسي. والحب المعرفي متصل بصفة العلم الإلمي وبحاسة البصر الإنسانية في بعدها الروحي أو البصيرة، وبمفعولا المادي أو البصر الحسي.

ومن ثُّ كان الترابط بين بعديْ الوجود أساس الضمير الديني: الشهادة والغيب. فالغيب حاضرٌ في الشاهد لكون الشاهد دالاّ على الغائب، وذلك هو المعنى العميق لكل معرفة: إذهي إدراكُ للعلل الغائبة في المعلولات الشاهدة لوحدة الأمرين: وحدةٌ وجهاها الغائب الحاضر في الشاهد (العلة-المدلول) والشاهد الدال على الغائب (المعلول-الدال). والحب السلطائ متصل بصفة الإرادة الإلمية وبحاسة الشمّ الإنسانية في بعدها الروحي أو الثّميمة. وبمفعولها المادي أو الشم الحسي. ولهذه العلة كانت الوحدة الأصلية بين الديني والسياسي: فالسياسي هو ما يقبل التحقيق التاريخي المتدرج من الديني، والديني هو ما يشد السياسي إلى المطلق. ذلك أن إشكالات الإنسان الوجودية ضربان: منها ما يقبل العلاج والحل النسبيين بتوسط العمل السياسي؛ وقاية بالتربية وعلاجا بالنظام، ومنها ما لا يقبل العلاج والحلَّ النسبيين لكوفا جوهرَ الوجود الميتافيزيقي الثابت للإنسان، فلا يكون تصورها إلا نظريا في الفكر الديني الصوفي والفلسفي العلمي. والحب الوجودي متصل بصفة الوجود الإلهي وبحاسة السمع الإنسانية في بعدها الروحي أو السّميعة (فالإصغاء لأناغيم الوجود وموسيقاه هو أسمى الإدراكات الإنسانية المناسب لأسمى المدركات) وبمفعولها المادي أو السمع 
الحسي. وفي هذا المعنى تكون جميع الحواس الإنسانية ضربا من الإنصات إلى ما ييثها الوجود من رسائل إلى الإنسان الذي يستكمل وجوده بقر ما يدرك من هذه الرسائل الآيات الدالة على المطلق.

إن السّميعة والثّميمة والبصيرة واللّميسة والذّويقة في الإدراك الباطن، والسمع والثم والبصر واللمس والذوق في الإدراك الظاهر تتحد في الذات المتجسمة المدركة لذاتما بتلك الحواس نفسها ببعديها الباطن والظاهر عند الشهود، إدراكا يشدها ضرورة إلى تجاوز مدركاتا لها واجتماعها في ذات مطلقة تناظرها، منبع إيجاد لمدركاتا ولإدراكاتا ولها هي أيضا. وتلك هي الصورة المحدوسة موضوعا أولَ لإدراك كل كائن عاقل لذاته بصفتها نسبة بين المتناهي واللامتناهي. لذلك فمن عرف نفسه عرف ربه: أي من أدرك وجود نفسه أدرك وجود ربه. وذلك هو جوهر الدليل الوجودي الاستخلافي أساسا للشهود، أصل القيم جميعا.

خاتمة

ليس من اليسير أن يؤمن المسلمون من جديد بأن رسالتهم تتمثل في إنقاذ الكون من عبث التأليَهْيْن المتلازمين للإنسان المتجبر (سلطن عبادة المال أو العجل المؤدي إلى الاستعباد المادي، وسلطان عبادة المثال أو تأليه الإنسان المؤدي إلى الاستعباد الروحي: النظام البنكي رمز "المافيا" المادية، والنظام الكنسي رمز "المافيا" الروحية)، تأليهيه المستندين إلى فلسفة الأفلاطونية -التوراتية المحدثة الجرمانية التي هي مجرد صياغة متنكرة لمبدأ التثليث المسيحي كما بينّا في بحث آخر:30 هذين التأليهين اللّذين عادا به إلى جاهلية جهلاء لا معبود فيها للإنسان إلاّ دنياه ولا مربوب له إلاّ هواه. و"مافية" معبوده الأول أطلقت يدّها في وجوده الدنيوي، و "مافية" معبوده الثاني أطلقت يدَها في وجوده الأخروي، فتقاسمتا آليات الاستعباد المفسد للإنسان والعالم إفسادا كان ذروته تَحَقِقَ مطالب الإصلاح الإنجيلي في رمز هذا الفساد الذي رأينا هيجل يعدّه تحقيقا

انظر أبويعرب المرزوقي: "الدليل الوجودي الحلولي أو شروط التحرّر من الأفلاطونية الححدثة لجرمانية"، إسلامية المعرفة، العدد الحادي

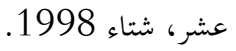


ناجحا لنظير فاشل هو الإسلام المحمدي حسب زعمه: الولايات المتحدة الأمريكية. 31 ولكن هيهات، فشتّان بين الثورة الإسلامية التي أعادت إلى أبعاد الإنسان الدنيوية معناها دون حصر الاستخلاف فيها، والإصلاح الإنجيلي الذي انتهى به إلى هذا المآل المقيت الساعي إلى ابتلاع العالم في عولمة الشر المفسد لباطن الإنسان بالتلوث الثقافي الأمريكي ومحيطه الطبيعي بالتلوث الصناعي الأمريكي.

فالمسلمون قد أصبحوا غافلين عن إدراك جوهر الروحانية الإسلامية والقيم المستندة إليها، لأن همهم صار محاكاة نظام المافية ببعديه المادي والروحي اللذين انقسم الوجود الإسلامي التاريخي بحسبهما فصرنا محكومين هذا الصراع. وعادت الروحانية الحلولية (في الطبيعة أو فيما بعدها، وهو معنى التقاء روحاينّة الشرق الأقصى القديم [البوذية] والغرب الأقصى المعاصر [الحلولي]، أي التقاء الروحانية التي بقيت دون الاستخلاف والروحانية التي تزعم أها تحاوزته) لتسيطرا بالقيم الثلاث المبتورة (عن أساسيها اللذين ذكّر بكما الإسلام: قيمة التعالي على الحاصل أو التوجيه، وقيمة شهود المطلق) من خلال الأفلاطونية -التوراتية المحدثة الجرمانيّة ببعديها الرأسمالي والاشتراكي بديلين عن النهج الإسلامي القويم.

لم نتجاوز في هذا المبحث الإشارة الخاطفة إلى أهم مقومات الروحانية الإسلامية، لأن تحديدها الدقيق يتجاوز جهود شخص واحد مهما أوتي من قوة، فضلا عن كون المقام لا يتسع لمثل هذه الأعمال الأساسية في الدراسات العقدية. ولعل المؤمنين المدركين لآثار التحريفين في الفكر الغربي الحديث يفرغون لمثل هذا الشأن الذي لا يقتصر على تحديد مقومات الانبعاث الإسلامي فحسب، بل هو يحدد الأسس التي يمكن للمسلمين بفضلها أن يغيروا قبلة الإنسان من جديد، وأن ينقذوا العالم مما تردَّى إليه بحكم سلطان هاتين المافيتين اللتين لم ييق في العالم ثابتا أمامهما إلاّ المقاومة الإسلامية. وتلك هي البداية الحقيقية للصحوة.

وقد أعاد الكاتب الياباني الأصل الأمريكي الانتماء فوكوياما في أطروحته عن غاية التاريخ المزاعم نفسها التي قال بها هيجل، إذ جعل 31

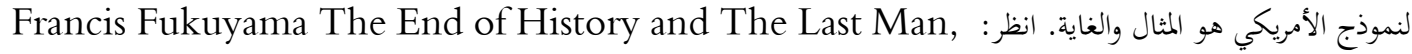

New York: The Free Press, 1992. 